\title{
Detection of Explosive Events by Monitoring Acoustically-Induced Geomagnetic Perturbations
}

\author{
D. L. Shaeffer, D. R. Rock, J. P. Lewis, S. I. Warshaw
}

February 17, 1999

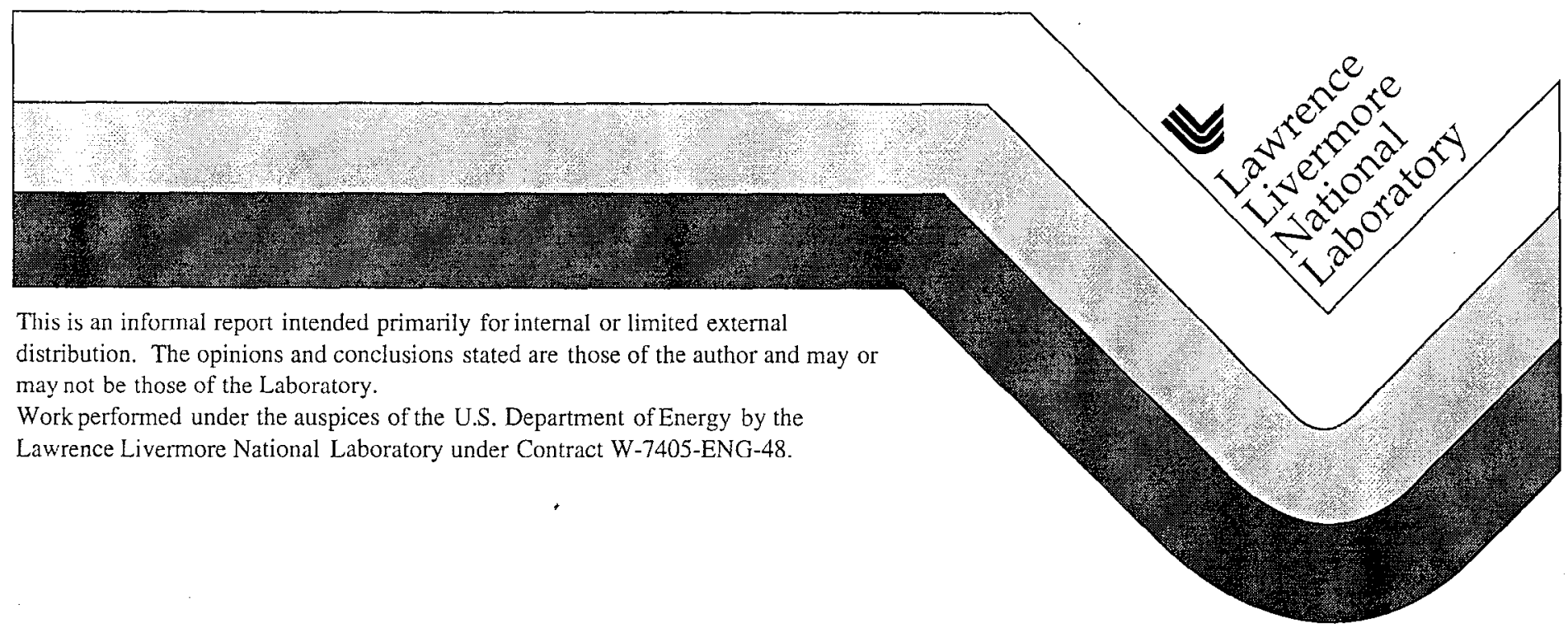




\section{DISCLAIMER}

This document was prepared as an account of work sponsored by an agency of the United States Government. Neither the United States Government nor the University of California nor any of their employees, makes any warranty, express or implied, or assumes any legal liability or responsibility for the accuracy, completeness, or usefulness of any information, apparatus, product, or process disclosed, or represents that its use would not infringe privately owned rights. Reference herein to any specific commercial product, process, or service by trade name, trademark, manufacturer, or otherwise, does not necessarily constitute or imply its endorsement, recommendation, or favoring by the United States Government or the University of California. The views and opinions of authors expressed herein do not necessarily state or reflect those of the United States Government or the University of California, and shall not be used for advertising or product endorsement purposes.

This report has been reproduced directly from the best available copy.

Available to DOE and DOE contractors from the Office of Scientific and Technical Information

P.O. Box 62, Oak Ridge, TN 37831

Prices available from (615) 576-8401, FTS 626-8401

Available to the public from the

National Technical Information Service

U.S. Department of Commerce

5285 Port Royal Rd.,

Springfield, VA 22161 


\section{Table of Contents}

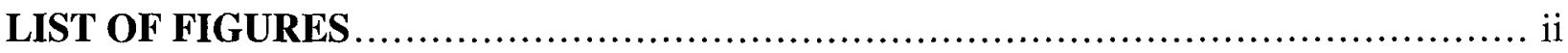

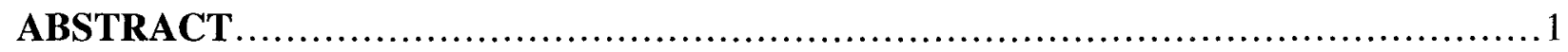

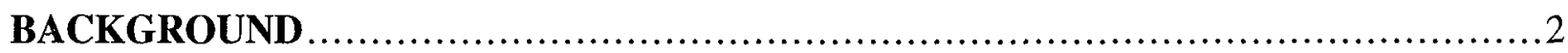

Objective ....................................................................2

Generation Mechanism for Geomagnetic Field Perturbations................................2

Alfvén (or hydromagnetic) Waves ....................................................... 3

Schumann Resonances and $Q$-Bursts ................................................... 8

Evidence for Acoustic-induced Geomagnetic Phenomena ............................... 11

EXPERIMENTAL SETUP ........................................................ 14

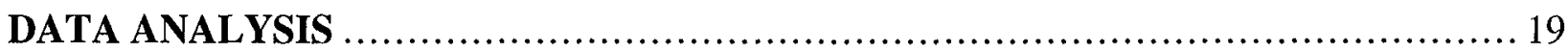

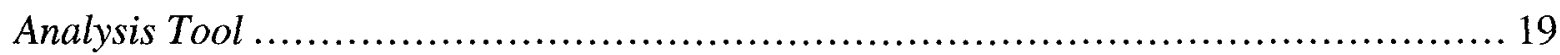

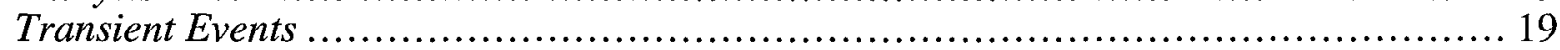

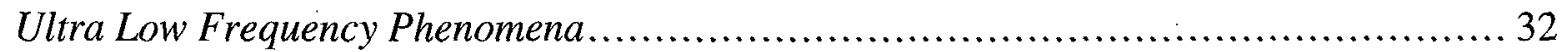

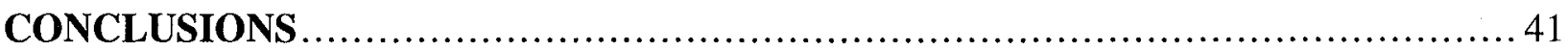

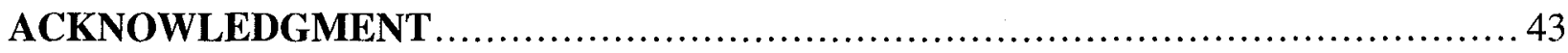

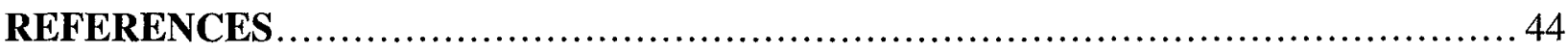

\section{APPENDIX A}

Q-BURST EXCITATION AND ENERGY FLUX IN THE SCHUMANN FREQUENCIES

CONTAINED WITHIN AN EXPLOSION-INDUCED HYDROMAGNETIC SOLITON

\section{APPENDIX B}

DERIVATION OF FOURIER TRANSFORM AND ENERGY SPECTRUM OF A SOLITON 


\section{List of Figures}

Figure 1. Simulation of the blast wave evolution for the Mill Race explosion $(600 \mathrm{~T}$ ANFO) which occurred at White Sands Missile Range, New Mexico, on 16 September 1981, at 12:35:40 local time. Horizontal extent and altitude variation of the compression and rarefaction phases of the $N$-wave are shown. Location of the ionospheric E region is depicted.

Figure 2. Altitude-dependent profile of the Alfvén velocity for daytime during maximum sunspot activity (from Jacobs and Watanabe, 1962).....................7

Figure 3. Idealized earth-ionosphere cavity in which lightning activity excites the Schumann resonances and $Q$-bursts.

Figure 4. The geographic locations of the two magnetic observatories (stations) are shown in relation to the Black Thunder Coal Mine.

Figure 5. Diagram of the equipment fielded at each of two magnetic observatories.

Figure 6. Histogram of seismic events that triggered our seismometer during the month of February 1997. The histogram is bimodal with peak occurrences in the early morning and mid-afternoon. This suggests that the seismic events are not random but follow the practices of open-pit coal mine operations.

Figure 7. Qualitative model of the propagation of the acoustic $N$-wave and its interaction with the $E$ and $F$ regions of the ionosphere. Current generation occurs near the peaks of the Hall and Pederson conductivity regions of the ionosphere.

Figure 8. Timing of acoustic-induced $E$ and $F$ region signals following a $2.4 \mathrm{kT}$ explosion at Black Thunder Coal Mine on 29 November 1996 at 1205 local time.

Figure 9. Timing of acoustic-induced $E$ and $F$ region signals following a $1.4 \mathrm{kT}$ explosion at Black Thunder Coal Mine on 1 December 1996 at 1310 local time.

Figure 10. Time domain traces and their Fourier transforms of two pulses observed following the $2.4 \mathrm{kT}$ explosion at BTCM on 29 November 1996. The decay time of about $0.5 s$ and the dominance of the Schumann resonances are characteristic of $Q$-bursts.

Figure 11. Waveform and spectrogram in the time interval 300 to $400 \mathrm{~s}$ following the explosion-induced seismic trigger associated with the $2.4 \mathrm{kT}$ explosion at BTCM on 29 November 1996. The Q-burst associated with the N-wave interaction in the E region is clearly evident above the noise in the time domain at $372.6 s$ and is even more enhanced in the spectrogram. 
Figure 12. Waveform and spectrogram in the time interval 500 to $600 \mathrm{~s}$ following the explosion-induced seismic trigger associated with the $2.4 \mathrm{kT}$ explosion at BTCM on 29 November 1996. The Q-burst associated with the $N$-wave interaction in the $F$ region is clearly evident above the noise in the time domain at $565 s$ and is even more enhanced in the spectrogram.

Figure 13. E and $F$ region signals apparently associated with two unannounced explosions that were separated in time by $4 \min 24 \mathrm{~s}$.

Figure 14. Ground motion caused by direct explosion-induced acoustic signal shakes the magnetometers and generates a magnetic signal. Calculated speed of propagation for the observed arrival times was very close to the ambient speed of sound in air.

Figure 15. Comparison of spectrograms of background data (top two spectrograms) with data obtained from a $1.52 \mathrm{kT}$ explosion (bottom two spectrograms). The spectrograms are plots of contours of constant spectral intensity ( gamma squared per $\mathrm{Hz}$ ) as a function of frequency $(\mathrm{Hz}$-vertical scale) and time ( $s-$ horizontal scale). Intensity appears to be enhanced above background after explosion. The time domain waveform is displayed above each spectrogram. The origin of the time axis coincides with the seismic trigger............................................................... 33

Figure 16. Inter-site comparison of north-south and east-west magnetometer responses following an explosion with yield of $1.21 \mathrm{kT}$. The top two traces are the north-south responses for observatories \#2 and \#1, respectively. The bottom two traces are the east-west responses for observatories \#2 and \#1, respectively. The signals look the same at both sites. They also look similar to pc 2-3 micropulsations, but they appear to be explosion-induced in the $F$ region.

Figure 17. Horizontal polarization of early and late time data recorded at observatory \#1 following a $0.490 \mathrm{kT}$ explosion on 11 January 1998. Fifty seconds of north-south magnetometer data are plotted against east-west data. Random polarization is observed at early time while elliptical polarization is observed at late time.

Figure 18. Horizontal polarization of early and late time data recorded at observatory \#1 following a 0.659 kT explosion on 13 February 1998. Fifty seconds of north-south magnetometer data are plotted against east-west data. Random polarization is observed at early time while elliptical polarization is observed at late time.

Figure 19. Horizontal polarization of early and late time data recorded at observatory \#2 following a $0.659 \mathrm{kT}$ explosion on 13 February 1998. Fifty seconds of north-south magnetometer data are plotted against east-west data. Random polarization is observed at early time while elliptical polarization is observed at late time. 
Figure 20. Horizontal polarization observed for three different fifty second time frames at observatory \#2 on 24 November 1997 during a time period when no seismic activity occurred-i.e., we received no seismic triggers from explosions or other seismic activity.

Figure A-1. Soliton waveform as a function of time. The fit was made to a classical soliton wave shape (Main, 1994) with parameter values reported by Gal'perin et al. (1986). The pulse width was taken to be the width at which the amplitude was 0.1 times the value of the peak amplitude.... 50

Figure A-2. Normalized energy spectrum of the soliton versus dimensionless frequency, p.... 53

Figure B-1. Normalized magnitude of the Fourier transform of the soliton as a function of dimensionless frequency, 58 


\begin{abstract}
The Black Thunder Coal Mine (BTCM) near Gillette, Wyoming was used as a test bed to determine the feasibility of detecting explosion-induced geomagnetic disturbances with groundbased induction magnetometers. Two magnetic observatories were fielded at distances of $50 \mathrm{~km}$ and $64 \mathrm{~km}$ geomagnetically north from the northernmost edge of BTCM. Each observatory consisted of three separate but mutually orthogonal magnetometers, Global Positioning System (GPS) timing, battery and solar power, a data acquisition and storage system, and a three-axis seismometer. Explosions with yields of 1 to $3 \mathrm{kT}$ of TNT equivalent occur approximately every three weeks at BTCM. We hypothesize that explosion-induced acoustic waves propagate upward and interact collisionally with the ionosphere to produce ionospheric electron density (and concomitant current density) perturbations which act as sources for geomagnetic disturbances. These disturbances propagate through an ionospheric Alfvén waveguide that we postulate to be leaky (due to the imperfectly conducting lower ionospheric boundary). Consequently, wave energy may be observed on the ground. We observed transient pulses, known as Q-bursts, with pulse widths about $0.5 s$ and with spectral energy dominated by the Schumann resonances.

These resonances appear to be excited in the earth-ionosphere cavity by Alfvén solitons that may have been generated by the explosion-induced acoustic waves reaching the ionospheric $E$ and $F$ regions and that subsequently propagate down through the ionosphere to the atmosphere. In addition, we observe late time (> 800 s) ultra low frequency (ULF) geomagnetic perturbations that appear to originate in the upper $F$ region $(\sim 300 \mathrm{~km})$ and appear to be caused by the explosion-induced acoustic wave interacting with that part of the ionosphere. We suggest that explosion-induced $Q$-bursts may be discriminated from naturally occurring $Q$-bursts by association of the former with the late time explosion-induced ULF perturbations. We also present evidence for an acoustically-induced magnetic signal at both magnetic observatories, indicating that magnetometers act as highly sensitive detectors of acoustically-induced ground motion. Further experimental and theoretical work are required to improve confidence in these conclusions.
\end{abstract}




\section{Background}

\section{Objective}

The objective of the work to be described here is to assess the feasibility of detecting explosive events by ground-based monitoring of low frequency $(-0.01 \mathrm{Hertz}[\mathrm{Hz}]$ to $50 \mathrm{~Hz})$ perturbations in the Earth's magnetic field. The monitoring was accomplished with the use of induction magnetometers aligned in three mutually orthogonal directions, viz., vertical, northsouth and east-west.

\section{Generation Mechanism for Geomagnetic Field Perturbations}

We now briefly describe the process that we think generates the magnetic field perturbations from ground-based explosions. An atmospheric or surface (ground or water) explosion creates a blast wave that eventually develops into a finite amplitude acoustic $\mathrm{N}$-wave-consisting of compression followed by rarefaction-in the atmosphere. Initially, the blast wave may have time duration as long as a few seconds (s). In the case of a ripple-fired mining explosion many smaller blast waves will form $\mathrm{N}$-wave trains which should eventually coalesce into a larger $\mathrm{N}$-wave. The parts of these acoustic waves that propagate upward through the atmosphere grow in amplitude as they progress. Due to the approximate exponential decrease in air density with increasing altitude, this growth is approximately exponential with altitude, as required to conserve energy and momentum. This growth will be mitigated to some extent by losses, including viscosity and geometrical spreading of the wave front. However, in general the blast-generated wave (or waves) will become an $\mathrm{N}$-wave by the time it reaches the $\mathrm{E}$ region of the ionosphere. (The ionosphere is the partially ionized region of space located from about $50 \mathrm{~km}$ above the Earth's surface to roughly $500 \mathrm{~km}$ altitude. The $\mathrm{E}$ and $\mathrm{F}$ regions of the ionosphere are located between about $90-120 \mathrm{~km}$ altitude and $120-500 \mathrm{~km}$ altitude, respectively.) In addition, the pulse width of the $\mathrm{N}$-wave may stretch to as long as a few tens of seconds at lower ionospheric altitudes.

The combined action of three physical processes_-viz., conservation of energy and momentum, nonlinear advection, and dissipation-determines the amplitude, shape and frequency content of the $\mathrm{N}$-wave as it propagates upward (Warshaw, 1980; Warshaw and DuBois, 1981). Growth in amplitude resulting from propagation into the more rarefied air at high altitudes enhances the high frequency as well as the low frequency content of the wave. Nonlinear advection causes a stretching of the pulse width thereby enhancing the low frequency content of the wave. The leading and trailing edges of the $\mathrm{N}$-wave, having positive and negative fluid velocities, respectively, each move away from the zero point crossing at the center of the 
$\mathrm{N}$-wave as the wave propagates. It is this stretching that increases the wave's fundamental period, which itself is lower in frequency than the frequencies inherent in the sharper leading and trailing edges of the $\mathrm{N}$-wave. As the propagation continues the amplitude progressively grows and causes further stretching. Dissipation due to kinematic viscosity becomes important as the wave enters the $\mathrm{D}$ region of the ionosphere. This dissipation varies inversely with air density, which decreases with increasing altitude. Dissipation causes a rounding of the sharp rising and falling edges, and leads to a decrease in the high frequency content of the wave. Overall we see that there is an increase in the low frequency content relative to the high frequency content in the $\mathrm{N}$-wave as it propagates upward. Nevertheless, as the experimental results shown in the report by Warshaw and Dubois (1981) indicate, some higher frequency energy still remains in the $\mathrm{N}$-wave even at ionospheric altitudes. In fact, the $\mathrm{N}$-wave is scen to have energy in the frequency band from about $0.01 \mathrm{~Hz}$ up to approximately $10 \mathrm{~Hz}$ or more.

This $\mathrm{N}$-wave phenomenology just described is realistically and graphically illustrated by the simulation results shown in Figure 1 for the progression of a blast wave from a single explosion on the ground to the ionosphere. This simulation successfully and accurately accounted for the ionospherically measured results of the Mill Race event of September 1981, and was carried out by Warshaw and Dubois (1981) from which the figure details were taken. Contours of pulse strength in any vertical plane through the detonation point are shown for this blast wave every 100 seconds from 200 to 800 seconds after detonation. These contours show clearly the gradual growth and lengthening of the $\mathrm{N}$-wave aspect, which is the profile of the blast wave amplitude along the direction of travel of any part of the blast wavefront.

We further suggest that when the acoustic disturbance reaches the ionosphere (Fig. 1) it interacts collisionally with the charged constituents to generate electrical currents in the E and F regions where the Hall and Pederson electrical conductivities (Rishbeth, 1969; Shaeffer, 1971) have their peak valucs. These localized peaks appear at approximatcly 120 and 250 kilometcrs $(\mathrm{km})$, respectively. These currents become sources for generation of two different modes of magnetic disturbances. One, called an Alfvén wave (or a hydromagnetic shear wave), propagates along geomagnetic field lines, and the other, called a modified Alfvén wave (or a hydromagnetic compressional wave), propagates isotropically.

\section{Alfuén (or hydromagnetic) Waves}

The ionosphere may be considered a partially ionized, approximately electrically neutral, plasma composed of electrons and various species of ions. The ions may be negatively or 
positively charged and may be singly or multiply ionized. The electronic and ionic population densities vary with altitude (see Kelly, 1989; or Rishbeth and Garriott, 1969). The ionosphere is also permeated by the Earth's magnetic field. Such magnetized plasma may sustain a variety of waves that propagate through the plasma when it is perturbed locally. This is particularly true in the $\mathrm{E}$ and $\mathrm{F}$ regions of the ionosphere where collisions between charged particles are much less frequent than in the $\mathrm{D}$ region (about $50 \mathrm{~km}$ to $90 \mathrm{~km}$ altitude).

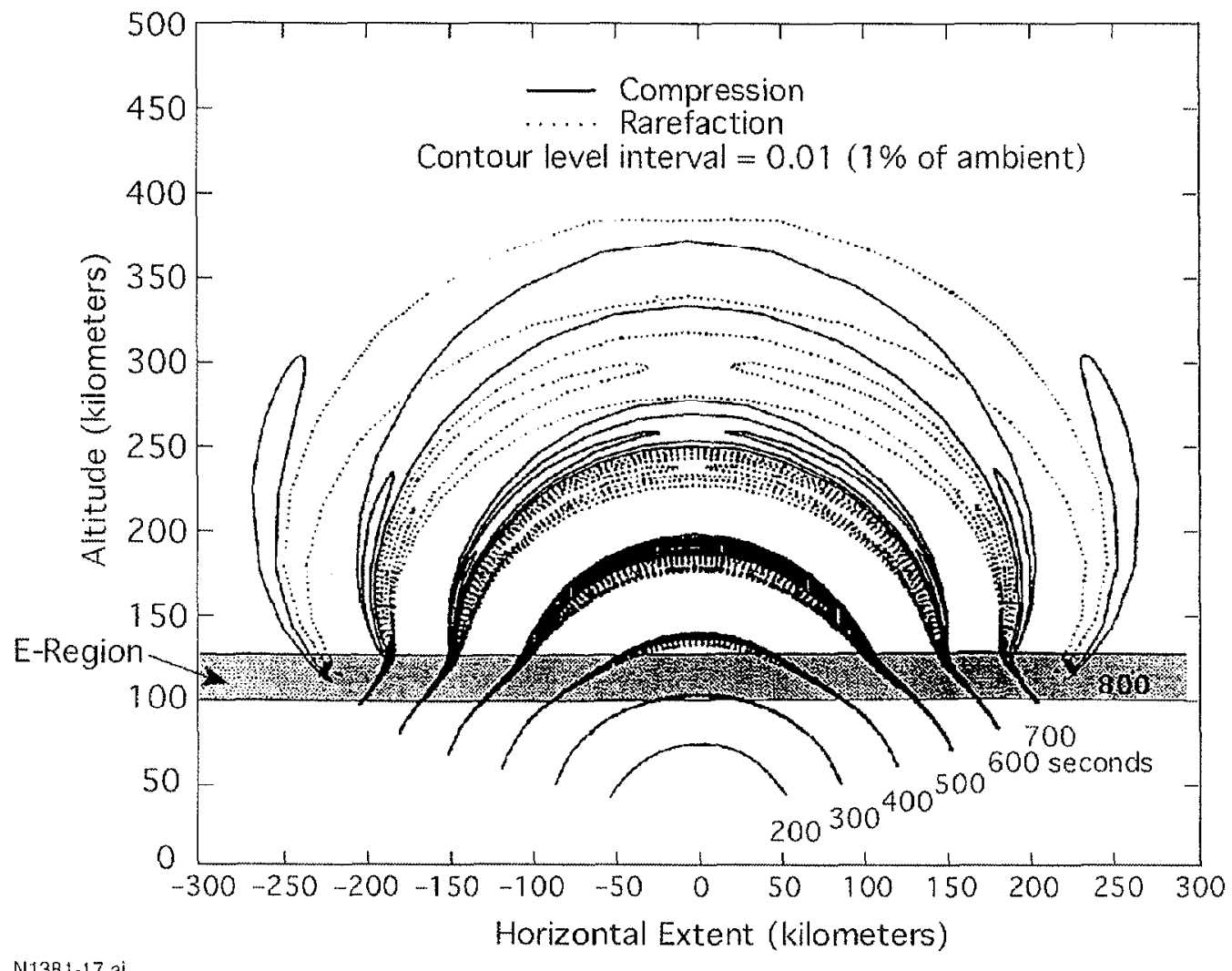

Figure 1. Simulation of the blast wave evolution for the Mill Race explosion (600 T ANFO) which occurred at White Sands Missile Range, New Mexico, on 16 September 1981, at 12:35:40 local time (from Warshaw \& Dubois 1981, 1983). Horizontal extent and altitude variation of the compression and rarefaction phases of the $N$-wave are shown. Location of the ionospheric $E$ region is depicted. 
Historically, investigation of the types of waves that may be generated and propagated through the ionospheric plasma began by considering the plasma to be electrically neutral, consisting of two particle species (electrons and ions) which are cold (zero temperature), and collisionless (Stix, 1992). In addition, the plasma was assumed homogeneous and immersed in a uniform static magnetic field. Under these conditions, and at wave frequencies, $\omega$, much less than the ion gyrofrequency, $\Omega_{\mathrm{i}}$-i.e., $\omega<<\Omega_{\mathrm{i}}$ - two types of waves were predicted to exist. (The ion gyrofrequency increases from about $24 \mathrm{~Hz}$ in the $\mathrm{E}$ region to about $40 \mathrm{~Hz}$ in the F region.) These were called hydromagnetic waves and have been labeled with different names by various investigators.

One type is now generally referred to as a pure Alfvén wave and the other as a modified Alfvén wave. (Such low frequency waves in a highly conducting fluid were first treated by $\mathrm{H}$. Alfvén [1942].) The former is anisotropic because its energy propagates at the Alfvén speed, $V_{A}$ (see below), only parallel or antiparallel to magnetic field lines. It is also sometimes called the slow mode because its phase velocity has a cosine dependence on propagation angle, $\theta$, where $\theta=0$ is in the direction parallel to the magnetic field lines. The pure Alfvén wave propagates in a torsional or shear mode so that the magnetic perturbations are perpendicular to the static geomagnetic field. The modified Alfvén wave is isotropic-i.e., energy propagates at the Alfvén speed at all angles to the magnetic field. In addition, the modified Alfvén wave propagates in the compressional mode. For propagation along magnetic field lines, both modes are circularly polarized, with the pure Alfvén wave being left-handed and the modified Alfvén wave being right-handed.

We note that some investigators have mistakenly described Alfvén waves as strictly magnetic perturbations with no associated electric fields. There are electric fields associated with Alfvén waves. However, these waves are magnetically dominated. The ratio of magnetic energy density to electric energy density in both the pure and modified Alfvén waves (Cross, 1988 , p. 21) is the just the square of the ratio of the speed of light, c, to the Alfvén speed, $\mathrm{V}_{\mathrm{A}}$. This ratio varies with altitude and may be as large as 1000 (Jacobs and Watanabe, 1962). Consequently, the magnetic energy density may be as much as six orders of magnitude larger than the electric energy density.

The Alfvén speed, $V_{A}$, is given by

$$
V_{A}=\frac{B_{0}}{\sqrt{\mu_{0} \rho_{i}}}(\mathrm{~m} / \mathrm{s}),
$$


where $B_{0}$ is the static magnetic field (tesla), $\rho_{i}$ is the ion mass density $\left(\mathrm{kg} / \mathrm{m}^{3}\right)$, and $\mu_{0}$ $\left(4 \pi \times 10^{-7} \mathrm{H} / \mathrm{m}\right)$ is the magnetic permeability of free space. (In our case, $B_{0}$ is the magnitude of the Earth's magnetic field at the altitude at which Eq. (1) is being evaluated.) This cxpression implies that both types of Alfvén waves require the existence of a material medium in which they can propagate. In other words, Alfvén waves will not propagate in a vacuum, as electromagnetic waves do. The above formula also suggests that the propagation of a pure Alfvén wave along the magnetic field line in a magnetized plasma is analogous to the propagation of transverse waves on an ideal stretched string. On the string, the speed of propagation of the disturbance is just the square root of the ratio of the string tension to the mass per unit length of the string. Here, $B_{0}^{2} / \mu_{0}$ plays the role of string tension and $\rho_{\mathrm{i}}$ plays the role of string mass density.

We observe that the Alfvén speed varies with altitude through the ionosphere because of the altitude dependence of $B_{0}$ and $\rho_{\mathrm{i}}$. The altitude dependence of $\mathrm{V}_{\mathrm{A}}$ is depicted in Fig. 2 (Jacobs and Watanabe, 1962). Various researchers (Jacobs and Watanabe, 1962, 1963; Fujita, 1988; Fujita and Tamao, 1988) have argued that this profile, along with magnetic data, implies that a waveguide traps hydromagnetic energy in the range of pc 1 micropulsations $(\sim 0.1 \mathrm{~Hz}-5 \mathrm{~Hz})$. (Micropulsations are divided into various classifications, one of which is pc's, meaning “pulsations continuous." See Jacobs, 1970.) We expect this cavity to extend azimuthally around the Earth (Jacobs and Watanabe, 1962 and 1963; Fujita and Tamao, 1988; Fujita, 1988; Molchanov, 1992). We further anticipate that this waveguide will be leaky due to the imperfectly conducting boundaries of the cavity. Consequently, we think that wave field energy might be observable on the ground with appropriate instrumentation, such as induction magnetometers. 


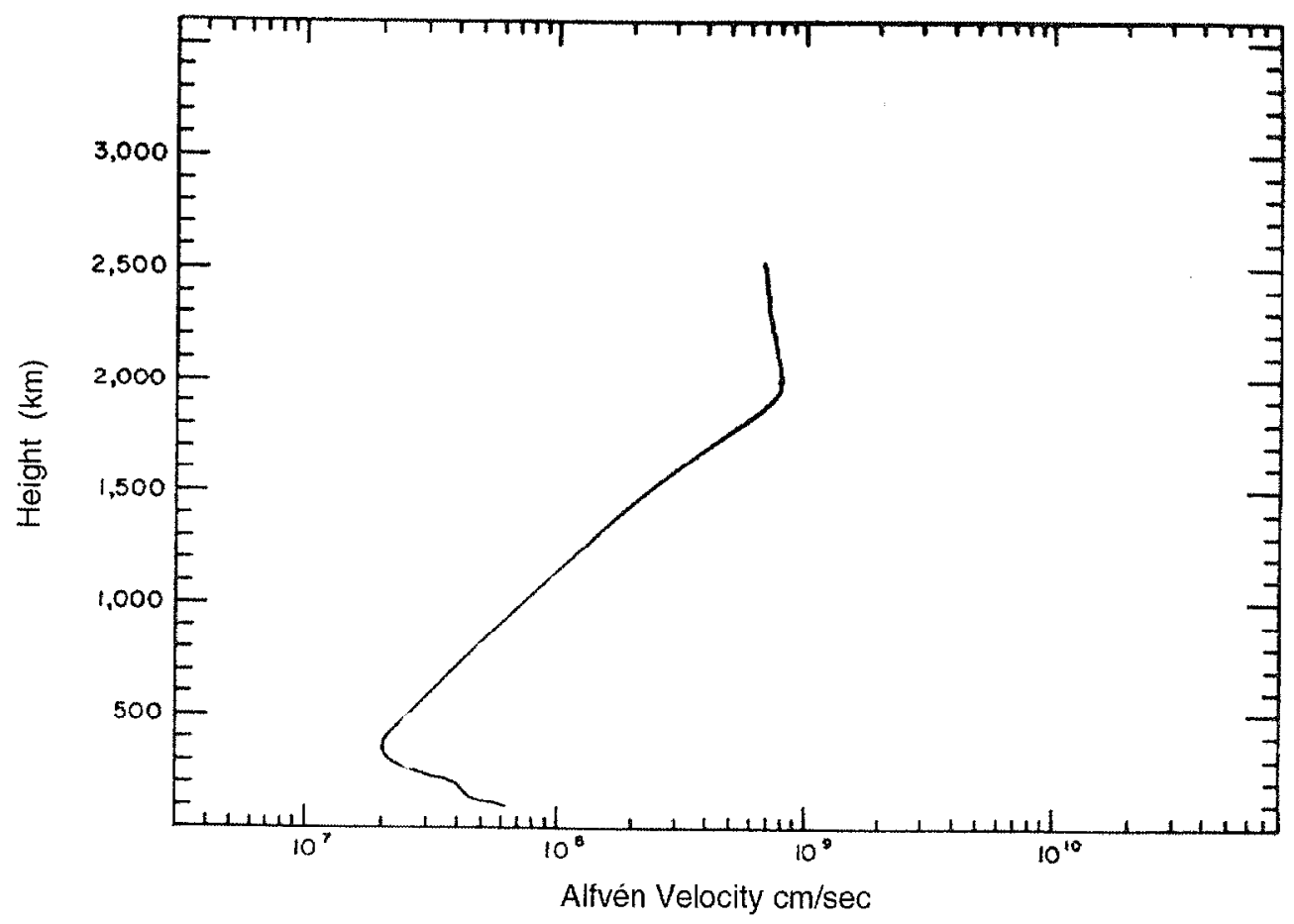

Figure 2. Altitude-dependent profile of the Alfvén velocity for daytime during maximum sunspot activity (from Jacobs and Watanabe, 1962). 


\section{Schumann Resonances and Q-Bursts}

Schumann resonances and Q-bursts are two other phenomena that are relevant to the present analysis. An electrically neutral cavity (Fig. 3) exists between the surface of the Earth and the ionosphere. This cavity has a natural electromagnetic resonance-called the Schumann resonance (first suggested by Schumann, 1952)—at about $7.8 \mathrm{~Hz}$, with harmonics at 14.1, 20.3, 26.4, 32.5, 39, and $45 \mathrm{~Hz}$ and higher (Sentman, 1995; Pierce, 1963). The first experimental evidence for the existence of these resonances was reported by Schumann and König (1954). This cavity acts as a global waveguide for electromagnetic energy supplied by worldwidc lightning activity. Lightning strokes occur worldwide at a rate of approximately 100 per second (Smith, 1961). Consequently, this waveguide is continuously excited by the incoherent addition of signals from multiple lightning strokes occurring nearly simultaneously, and the Schumann resonances may be observed at essentially any point in time. Discrete excitations of the earthionosphere cavity by individual lightning strokes are generally not observable.

The ability of this cavity to store electromagnetic energy is described in terms of its Q-value, which is the angular frequency times the time-averaged energy stored in the cavity divided by energy lost from the cavity per unit time. The average $Q$ for the dominant transverse magnetic (TM) normal modes ranges from 3 to 6 . These resonances are often observed by Fourier analyzing time domain magnetic data, which are easier to obtain experimentally than the associated electric field data which tend to contain much more noise.

Occasionally, a large individual lightning stroke - called a superbolt (Turmann, 1977)-excites the cavity to an amplitude greater than that excited by the incoherent addition of several lightning strokes, so that a transient with a decay time determined by the $\mathrm{Q}$ of the earthionosphere cavity is generated. This phenomenon is called a Q-burst (Ogawa, 1966; Sentman, 1995; Sentman, 1989), and typically lasts about 0.5 second. A Q-burst is generally defined morphologically as an electromagnetic pulse that is dominated by energy at $8 \mathrm{~Hz}$-i.e., the fundamental Schumann resonance. 


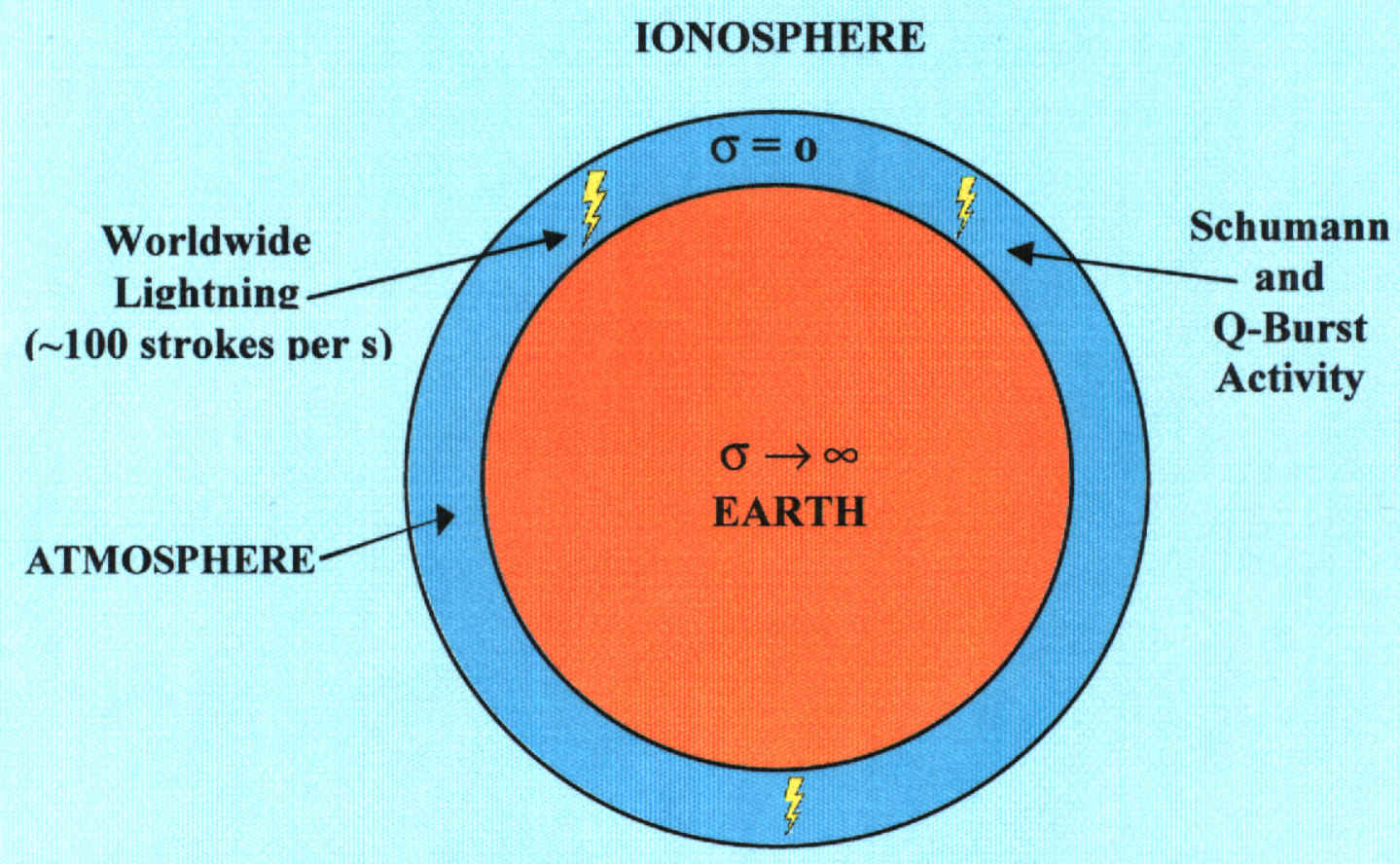

IONOSPHERE

( $\sigma$ finite, but large at lower boundary)

Figure 3. Idealized earth-ionosphere cavity in which lightning activity excites the Schumann resonances and Q-bursts. 
There remains an open question as to whether lightning is the only phenomenon which can excite the Schumann resonances. In fact, Abbas (1968) has argued that hydromagnetic waves (Alfvén waves) may also excite the Schumann resonances. We now recall that Gal'perin et al. (1986) reported the detection of a magnetic impulse that they interpreted as an Alfvén soliton generated by interaction of the neutral acoustic wave from the MASSA explosion with the dynamo (Rishbeth, 1971; Rishbeth, 1997; Maeda and Kato, 1966) portion of the ionospheric F region to produce strong field-aligned currents. (MASSA is the Russian acronym for "Magnetosphere-Atmosphere Coupling during Seismic Impact.") A self-consistent theoretical interpretation of this phenomenon was provided by Pokhotelov et al. (1994) in terms of a onedimensional Alfvén soliton. This Alfvén soliton had a duration of $0.08 \mathrm{~s}$ along with a steep rising front, and therefore has energy in the Schumann frequency band. Based on Abbas's estimates of the ionospheric transmission coefficients (Abbas, 1968; also see Greifinger and Greifinger, 1965; and Shaeffer, 1971), the Alfvén soliton would require energy flux in the range of $10^{-8} \mathrm{~W} \mathrm{~m}^{-2} \mathrm{~Hz}^{-1}$ to $3 \times 10^{-7} \mathrm{~W} \mathrm{~m}^{-2} \mathrm{~Hz}^{-1}$ to penetrate through the ionosphere into the atmosphere and cxcitc the fundamental Schumann resonance. The cnergy flux $\left(\mathrm{W} / \mathrm{m}^{2}\right)$ in the Alfvén wave is the magnitude, $S$, of the Poynting vector, and is given (Cross, 1988) by

$$
S=\frac{b^{2} V_{A}}{\mu_{0}},
$$

where $b$ is the magnetic field perturbation associated with the Alfvén shear wave, $V_{A}$ is the Alfvén velocity, and $\mu_{0}$ is the magnetic permability of free space $\left(4 \pi \times 10^{-7} \mathrm{H} / \mathrm{m}\right)$. Using the value of $117 \times 10^{-9}$ tesla measured by Gal'perin et al. (1986) and the associated Alfvén velocity of $10^{6} \mathrm{~m} / \mathrm{s}$, we obtain an energy flux of $10^{-2} \mathrm{~W} / \mathrm{m}^{2}$. We calculate the energy flux per unit frequency at the fundamental Schumann resonance to be approximately $1.3 \times 10^{-5} \mathrm{~W} \mathrm{~m}^{-2} \mathrm{~Hz}^{-1}$ (See Appendices A and B.) This is approximately a factor of 40 greater than the largest threshold value calculated by Abbas. We conclude that the energy flux of the Alfvén soliton generated by the MASSA explosion (250 T) was sufficient to produce a Schumann Q-burst. This suggests that a connection exists between sub-ionospheric explosions and Alfvén waveinduced Schumann activity in the form of Q-bursts. 
This also indicates why we have selected the particular range of frequencies on which to concentrate in this current work. The Schumann resonances, Alfvén waves, and the atmospherically-modified nonlinearly propagating explosion-induced acoustic waves all have energy within the frequency range of $0.01 \mathrm{~Hz}$ to $50 \mathrm{~Hz}$.

\section{Evidence for Acoustic-induced Geomagnetic Phenomena}

The fact that acoustically-induced geomagnetic disturbances are generated and detectable is supported by an abundance of evidence. Blanc (1985) has published a review of the impact of man-made and natural acoustic sources-e.g., chemical and nuclear explosions, volcanic eruptions, earthquakes, hurricanes, magnetic storms, polar aurora, rocket launches, etc-on the ionosphere. The first report of work that attempted to measure the effect of explosions on the ionosphere appears to be that of Daniels et al. (1960), which was conducted in support of American nuclear tests conducted in Nevada and in the Pacific. They used vertical incidence radio sounders to detect the times of arrival of explosion-induced acoustic pulses by observing the induced ionospheric electron density perturbations. In fact, Daniels et al. report the observation of two hydromagnetic waves (differing in velocity of propagation) of the types postulated above. Barry, Griffiths, and Taenzer (1966) reported on vertical-incidence radio sounding measurements of ionospheric disturbances caused by a surface chemical explosion consisting of 500 tons (T) of TNT. Warshaw and Dubois $(1981,1983)$ reported on their successful modeling of high frequency (HF) ionospheric sounding perturbation measurements obtained during the U.S. Mill Race surface chemical explosion ( $600 \mathrm{~T}$ of ANFO detonated at 12:35:40 local time (LT), 16 September 1981, at White Sands Missile Range, New Mexico, U.S.A.). Pitteway et al. (1985) also reported ionospheric electron density perturbation measurements, along with modeling, obtained during the Mill Race event.

During the late 1970's and early 1980's, U.S. scientists, under the auspices of the U.S. Department of Energy (DOE), probed the ionosphere with radar equipment, called ionosondes, to determine the ionospheric effects of a number of man-made and natural explosive events. The ionosonde measurements revealed that the electron density in the ionospheric $\mathrm{E}$ region was perturbed to levels of a few percent of ambient. (Electron density perturbations are a necessary intermediate step in the generation of geomagnetic disturbances of the type of concern here.) In addition, immediately following the U.S. Argus III high altitude nuclear test, both types of Alfvén waves were observed on the ground with magnetometers at eight different magnetic observatorics located worldwide, at distances ranging from $5500 \mathrm{~km}$ to $13,700 \mathrm{~km}$ from ground zero directly below Argus III (Berthold et al., 1960). This latter event demonstrated that the 
effects of the Alfvén waves generated by the explosion could be observed on the ground at global distances from the explosion point.

The Soviets also found evidence for the generation and propagation of acousticallyinduced magnetic disturbances. In the early 1980's, they conducted a large experiment (Al'perovich, 1982; Drobzhev et al., 1982; Al'perovich et al., 1985), called MASSA (Russian acronym for "Magnetosphere-Atmosphere Coupling during Seismic Impact"), to measure the ionospheric, geomagnetic and acoustic effects of a surface chemical explosion $(\sim 250 \mathrm{~T}$ TNT equivalent). They monitored the explosion with equipment onboard the French Aureol-3 satellite and detected a $100 \gamma\left(1 \gamma=10^{-5}\right.$ gauss $=10^{-9}$ tesla $)$ perturbation, approximately five minutes after the cxplosion, at about $800 \mathrm{~km}$ altitude along the geomagnetic ficld lines that passed through the E region directly above the explosion. The perturbation had a velocity of propagation equal to the Alfvén velocity associated with the plasma and magnetic field environments existing at the location of the measurement. The perturbation also took the form of a soliton (Pokhotelov et al., 1996), characterized by a magnetic field having a sharply rising front. Furthermore, the Russians analyzed data (Gokhberg et al., 1992), obtained from Goddard Space Flight Center, recorded by instruments onboard the American Dynamic Explorer II (DE 2) satellite that was operating during the conduct of the American underground nuclear test (UGT) called Paliza. At that time, DE 2 was located in the southern hemisphere and positioned on geomagnetic field lines that passed through the E region located directly above Nevada Test Site (NTS). Although an Alfvén wave was not observed, a spot of electrostatic noise was observed. (It would have been extremely fortuitous for the satellite to have been in exactly the right position to have detected the Alfvén wave as it passed by. This is contrasted with the Aureol satellite, the position of which was coordinated with the conduct of the MASSA test.) The Russians developed a theory (Pokhotelov et al., 1994; Pokhotelov et al., 1996) that showed that the passage of an Alfvén soliton through the plasma at that location would have generated such persistent noise by means of an electrostatic plasma instability. Consequently, the observed phenomenon appears consistent with an acoustic wave emanating from the vertical motion of the ground containing the UGT and subsequently propagating to the E region above NTS, where an Alfvén wave was generated and subsequently propagated along the geomagnetic field lines to the southern hemisphere. According to this Russian theory, a tube of geomagnetic field lines would have been filled with the electrostatic turbulence. Some of the earlier experimental findings led Gokhberg (1983) to suggest using man-made explosions to experimentally probe the atmosphere, ionosphere, and magnetosphere. 
Natural phenomena have also been observed to produce geomagnetic perturbations. Perhaps the most notable was the Mount St. Helens explosion that occurred on 18 May 1980. It generated a disturbance that was detected at ground surface by a network of magnetometers fielded by the Air Force Geophysics Laboratory (AFGL) — now part of Phillips Laboratory, Bedford, Massachussetts, U.S.A.- - at various locations across the continental United States (Fougere and Tsacoyeanes, 1980; Knecht, 1985; Chi et al., 1996). The effects of the Mount St. Helens explosion were also observed on Doppler recordings, total ionospheric electron content (TEC) measurements, and microbaragraph measurements in Japan and reported by Tadahiko et al. (1982). The dominant frequency of this disturbance, however, was much lower $\left(\sim 10^{-3} \mathrm{~Hz}\right)$ than those comprising the Alfvén disturbances mentioned above. In addition, the gencration mechanism appears to be differcnt. The magnetic pulse associated with Mount St. Helens appears to have been caused by explosion-induced Lamb waves (Tadahiko et al., 1982) interacting with the geomagnetic field at ionospheric altitudes.

Theory also supports the ionospheric generation of geomagnetic perturbations by vertically propagating explosion-induced acoustic waves. Using a semi-spherical N-wave acoustic model provided by Warshaw and Dubois (private communication, 1981), Bernhardt (1982) performed two- and three-dimensional numerical simulations of the acoustic interaction with ionospheric plasma in the $\mathrm{E}$ region. He concluded that measurable magnetic field perturbations could probably be observed on the ground near the acoustic source. He recommended that an experimental program be established to validate the theoretical results. The work reported below appears to be the first systematic effort to do so. Aburjania et al. (1997) developed a theory for the transformation of vertically propagating long-wavelength acoustic waves into electromagnetic waves in the ionospheric plasma. They obtained a dispersion relation that shows the nonlinear effect of an acoustic signal on the ionosphere. Stubbe et al. (1982) show experimentally that an extremely low frequency (ELF) pulse is radiated when the ionosphere is heated with a much longer radio frequency (rf) pulse. Related work is reported by Rowland et al. (1996). Pokhotelov et al. (1996) have advanced a theory to explain the observation of an Alfvén soliton by instrumentation onboard the Aureol-3 satellite (Gal'perin et al., 1986) that monitored the MASSA experiment (Al'perovich, 1982). Molchanov (1992) has developed theory to show that acoustic disturbances from earthquakes are transformed into Alfvén waves (pure and magnetosonic) in the lower ionosphere in the frequency range $0.1 \mathrm{~Hz}$ to $10 \mathrm{~Hz}$. 


\section{Experimental Setup}

In October 1996 we established an experimental program to pursue our objective by taking advantage of commercial open-pit coal mine blasting activity at the Black Thunder Coal Mine (BTCM) near Gillette, Wyoming (Fig. 4). This operation is apparently the largest of its kind in the world. Explosions occur there approximately every three weeks and have yields equivalent to 1-3 kilotons (kt) of TNT. The explosions occur in several hundred holes drilled in the ground in a regular pattern - based on technological practice developed over a century of mining experience-over approximately ten thousand square meters, and are ripple-fired in a suitable timing sequence. Several seconds may be required to complete the firing sequence. A hillside as long as a quarter of a mile in length is typically removed in onc ripple-firc sequence in order to uncover coal that will subsequently be mined. The effect of the ripple explosion is to peel the side of the hill off similar to the peeling of an onion layer.

We fielded two magnetic observatories 31 miles $(50 \mathrm{~km})$ and 40 miles $(64 \mathrm{~km})$ geomagnetically north of the northern boundary of BTCM (Fig. 4). The two observatories are located at geographic coordinates $44^{\circ} 8^{\prime} 49.6^{\prime \prime} \mathrm{N}, 105^{\circ} 10^{\prime} 14.8^{\prime \prime} \mathrm{W}$ (Observatory \#1) and at $44^{0} 14^{\prime} 15.8^{\prime \prime} \mathrm{N}, 105^{\circ} 3^{\prime} 18.8^{\prime \prime} \mathrm{W}$ (Observatory \#2). Each observatory contained three mutually perpendicular induction magnetometers, a three-component seismometer, a data acquisition and storage system, Global Positioning System (GPS) timing receivers, and battery power backed up with solar panel power (Fig. 5). The instruments were buried to protect them from weather and from animals. Wooden fences secured with non-metallic parts were emplaced around the perimeter of the plot of ground in which the instruments were buried to protect them from grazing cattle and wildlife.

The magnetometers were designed and manufactured by ElectroMagnetics Instruments (EMI), Inc., in Richmond, California. At each observatory, we used two of EMI's model BF-7 magnetometers to measure horizontal magnetic fields, and one model BF-4 to measure vertical magnetic fields. Both types of magnetometers are recommended for operation at frequencies between $0.0001 \mathrm{~Hz}$ and $1000 \mathrm{~Hz}$. The response of each is about 0.3 volts (V) per gamma. The $\mathrm{BF}$ series magnetic sensors are cylindrical in shape and consist of a high magnetic permeability material wrapped with many thousands of turns of wire. The BF-4 is $142 \mathrm{~cm}$ in length and the BF-7 is $104 \mathrm{~cm}$ in length. Each sensor has a matched low noise preamplifier, and the sensor design is optimized to maximize noise performance for a given length-to-weight specification. 


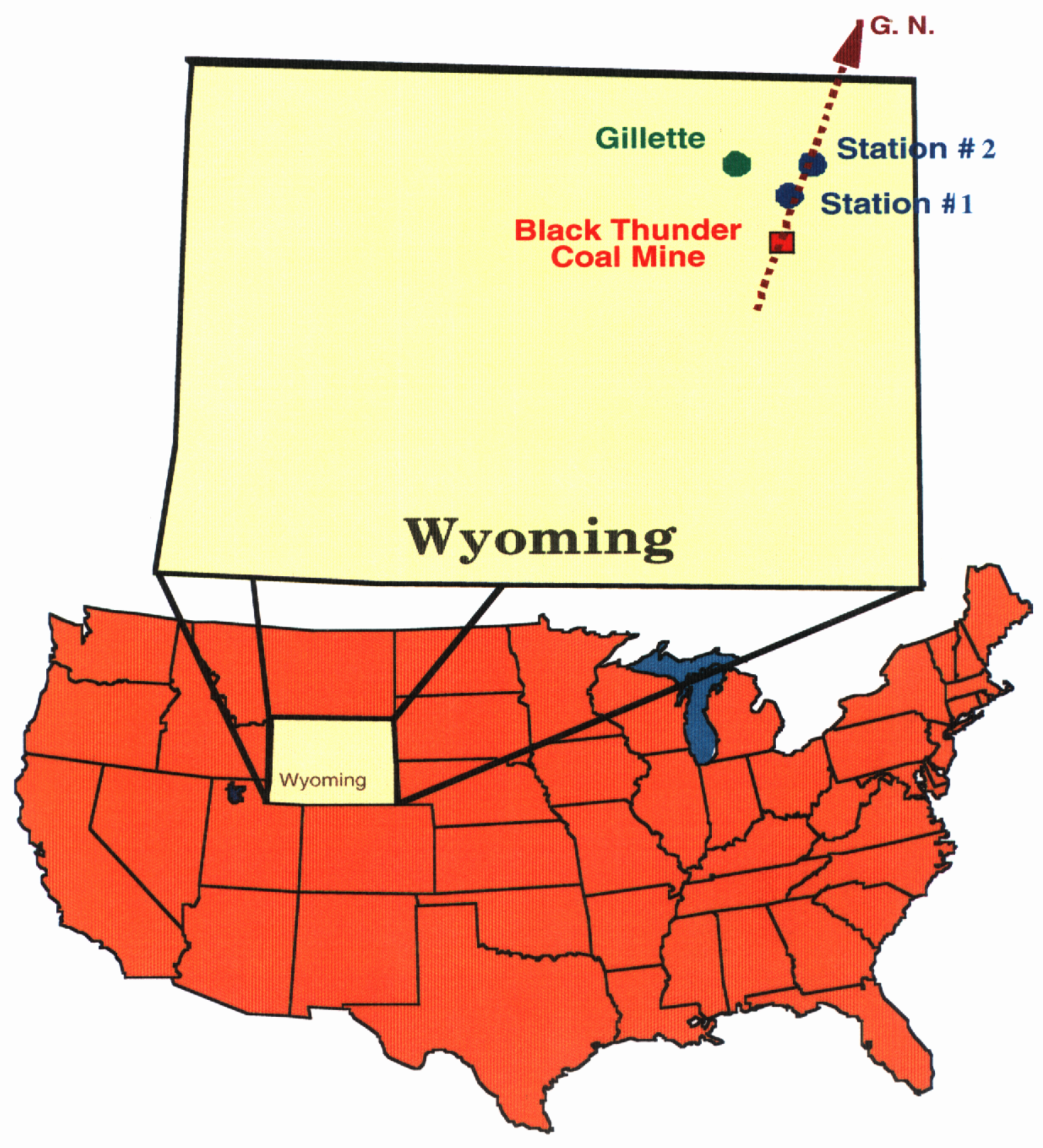

Figure 4. The geographic locations of the two magnetic observatories (stations) are shown in relation to the Black Thunder Coal Mine. 


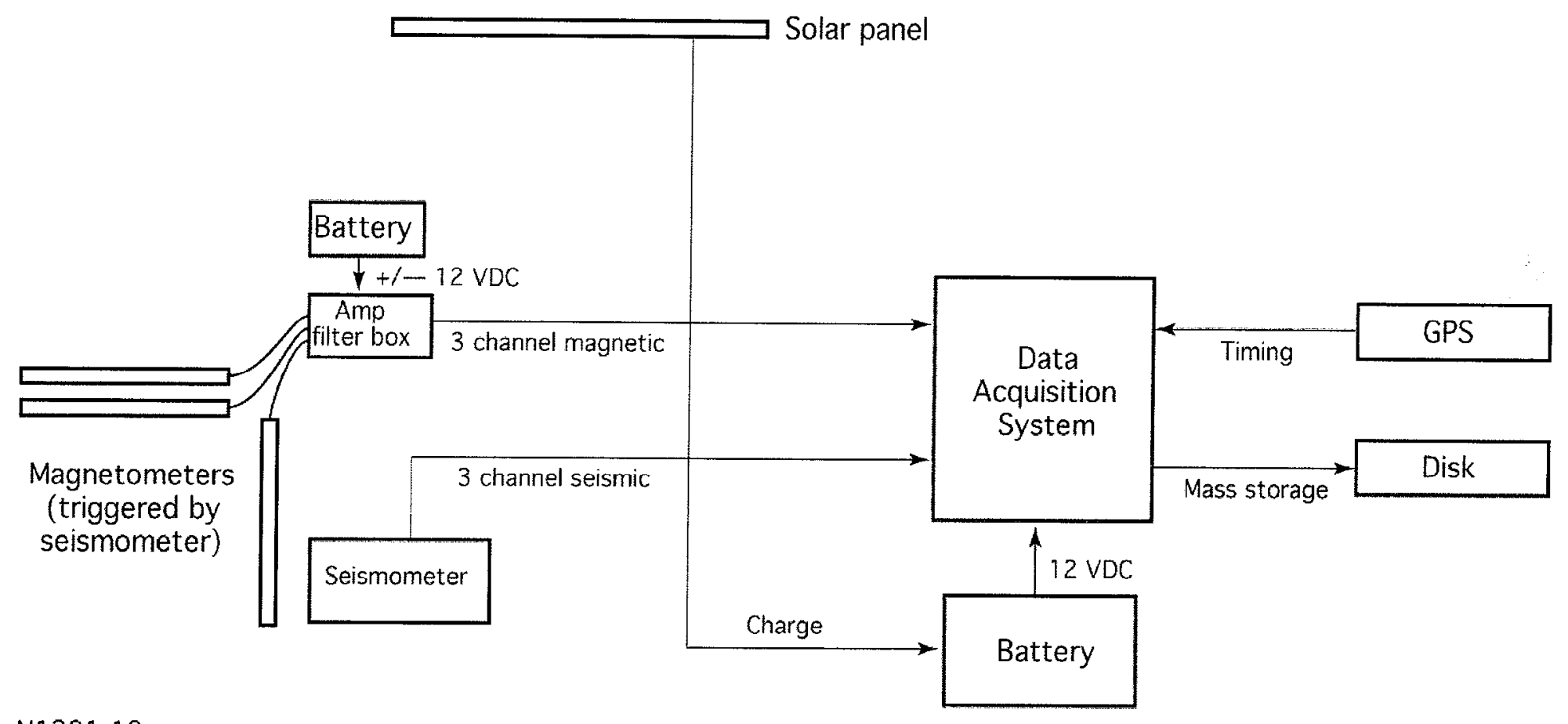

N1381-19

Figure 5. Diagram of the equipment fielded at each of two magnetic observatories. 
The data acquisition system (DAS) was manufactured by Refraction Technology, Inc. (REFTEK), Dallas, Texas. It is a multi-purpose system with multiple data channels and multiple triggering schemes-e.g., time, event, and cross triggering. The REFTEK DAS which we used contained three 16-bit channels and three 24-bit channels which we used for seismic and magnetic data collection, respectively. This unit also had a GPS time recording capability.

The magnetometers and data acquisition system were programmed to remain dormant until the seismometer sensed a signal generated by the mining explosion. The magnetometers were then turned on and magnetic data collection began. Magnetic signals due to the explosion were not seen immediately because the acoustic disturbance required about 5-6 min to propagate to the ionospheric $\mathrm{E}$ region. Our equipment recorded 20 minutes of data for each event. This recording strategy was adopted in order to conserve space on the computer hard drive where data were stored, and at the same time allow for acoustic pulse propagation to go well above the F region. Our observatories recorded numerous seismic and magnetic events, including events due to mining activities other than BTCM. There are approximately 15 open-pit coal mine operations in the northeast region of Wyoming. BTCM is however by far the largest operation and detonates the largest explosions.

The conclusion that these seismic events were caused by mining activity is supported by the data shown in Fig. 6. This is a histogram (number of seismic events versus time) of all seismic events that triggered our seismometers during the month of February 1997. If the events triggering our seismometers were of seismic origin, we would expect the histogram to show that the explosions occurred randomly in time. Instead we find that essentially all of the events occurred during daylight hours, and the peak activity occurs in the afternoon. This is consistent with the practice of coal mine operations. In fact, the conduct of explosions at nighttime for the purpose of mining coal is forbidden by Federal regulation. In addition, Wyoming is essentially aseismic, that is, earthquakes rarely occur. This evidence supports our premise that the seismic signals we detect are due to local mining activity. 


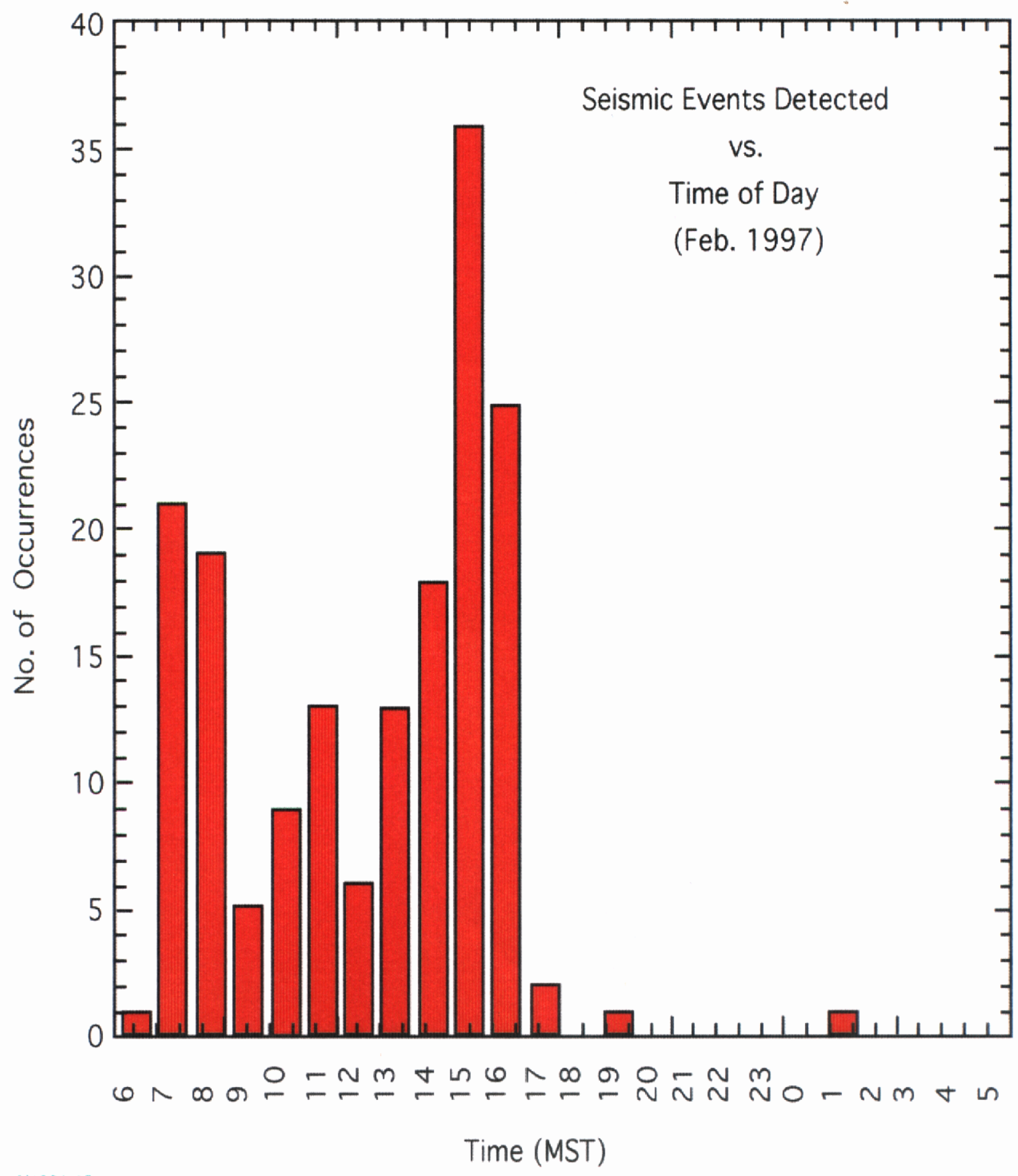

$\mathrm{N} 1381-15$

Figure 6. Histogram of seismic events that triggered our seismometer during the month of February 1997. The histogram is bimodal with peak occurrences in the early morning and mid-afternoon. This suggests that the seismic events are not random but follow the practices of open-pit coal mine operations. 


\section{Data Analysis}

\section{Analysis Tool}

The Seismic Analysis Code (Tapley and Tull, 1992) - called SAC — was used in all time domain and frequency domain analyses presented below. SAC was run within a LINUX environment on an IBM clone personal computer (PC). It was developed over a period of many years by scientists at Lawrence Livermore National Laboratory (LLNL) for the purpose of providing a versatile code to perform time domain and frequency domain analyses of seismic data, and was directly adaptable to the magnetic data analyzed here. SAC is an interactive program and can perform general arithmetic, Fourier transforms, various spectral estimation operations, filtering, decimation, interpolation, correlation, and many other operations on data files. SAC operates on a variety of computer platforms and was found to be particularly useful for our interests.

\section{Transient Events}

We used a qualitative model of the expected interaction of the upward propagating acoustic disturbance with the ionosphere, as shown in Fig. 7, to help analyze our data. The acoustic disturbance requires about $6 \mathrm{~min}$ to propagate to the $\mathrm{E}$ region of the ionosphere. We allow $\pm 40 \mathrm{~s}$ for uncertainty in the location of the region of maximum interaction, for natural variability in the height of this region, and for variations in the vertical profile of the speed of acoustic propagation in the atmosphere. Similarly, the acoustic disturbance requires about 10 min to reach the F layer of the ionosphere. Here too we allow an uncertainty of \pm 40 s for the same rcasons as above. The $F$ region is much broader in altitude-ranging generally from about $150 \mathrm{~km}$ to $500 \mathrm{~km}$-than the $\mathrm{E}$ region and so the uncertainty adopted here for the $\mathrm{F}$ region interaction is more uncertain itself than that adopted for the E region. Because of time and funding constraints, we decided that data collection and data analysis should have higher priority than developing the requisite theoretical models. In addition, some theory already exists, as cited above and as indicated by Warshaw (1980) and Warshaw and Dubois (1981). We anticipate that additional modeling - including acoustic propagation (based on the aforementioned theoretical work), magnetic field disturbance generation, and magnetic field disturbance propagation-will occur in the future. 


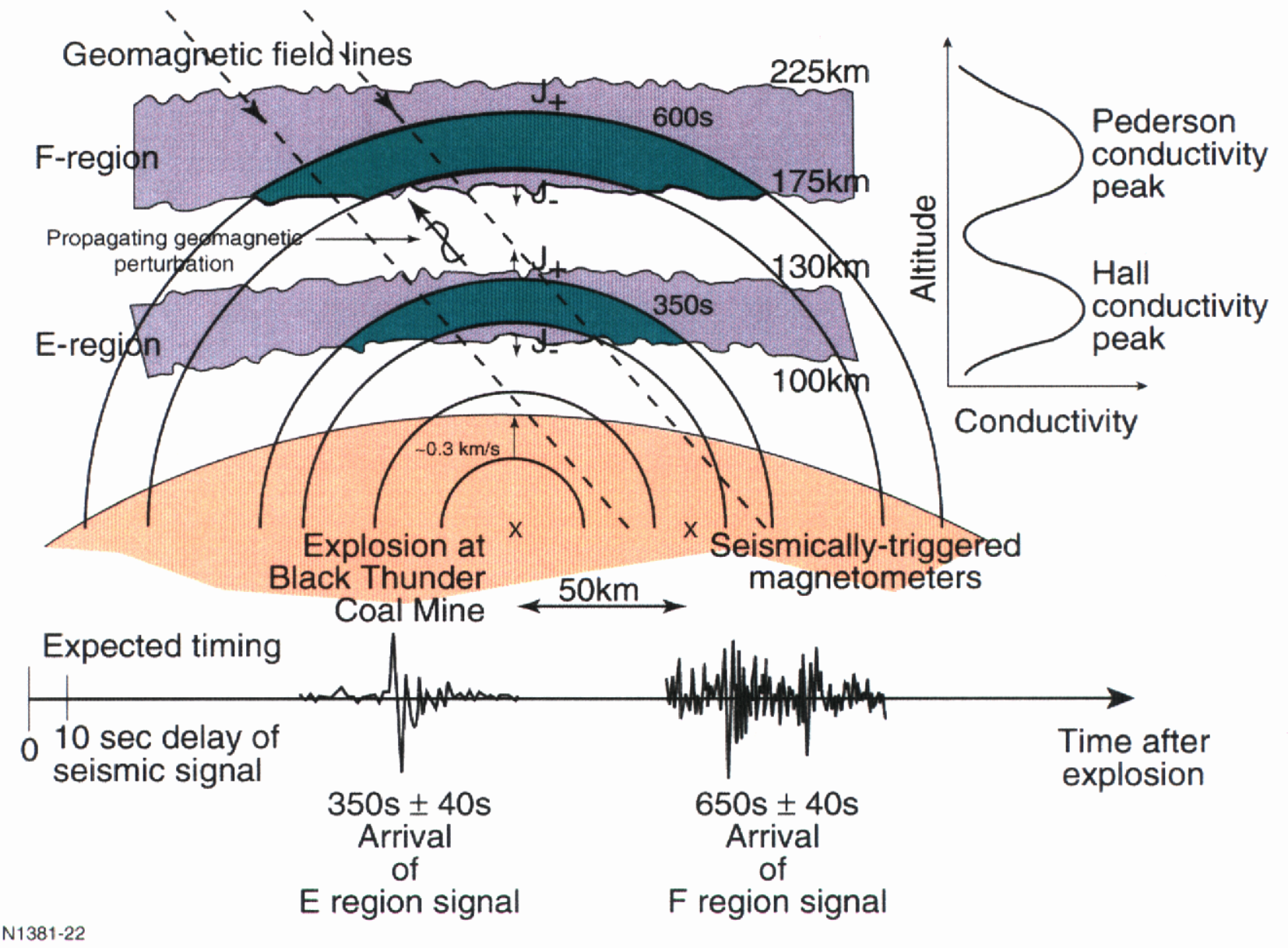

Figure 7. Qualitative model of the propagation of the acoustic $N$-wave and its interaction with the $E$ and $F$ regions of the ionosphere. Current generation occurs near the peaks of the Hall and Pederson conductivity regions of the ionosphere. 
The data for two events that appear to fit the timing model scenario described above are shown in Figs. 8 and 9. Time axes are shown at the bottoms of the figures. The lower axis in cach figure shows the time of arrival of the scismic signal that triggers the magnetometers about $10 \mathrm{~s}$ after the explosion, as well as the expected time of arrival of the magnetic signals generated in the $\mathrm{E}$ and $\mathrm{F}$ regions. Figure 8 applies to a $2.4 \mathrm{kT}$ explosion that occurred at BTCM on 29 November 1996, at 1205 LT. Two signals were observed at times that presumably correspond closely to interactions with the $\mathrm{E}$ and $\mathrm{F}$ regions, respectively. The traces appearing within the circles are expansions of the time axes at times when the two signals were observed. The same comments apply to the event recorded in Fig. 9, which corresponds to a $1.4 \mathrm{kT}$ explosion at BTCM at 1310 LT on 1 December 1996. In both events, the two signals occurred at times predicted by the qualitative timing model. In both cases, the F region signal is slightly larger than the E region signal. The magnetic signals scale approximately as the square of the ratio of the yields of the explosions, which suggests that there may be a nonlinear relation between explosion yield and the resulting magnetic field perturbation.

Figure 10 shows the time domain traces, along with their Fourier transforms, of the two pulses observed following the $2.4 \mathrm{kT}$ explosion at BTCM on 29 November 1996. The dashed lines in the top left figure show a $0.5 \mathrm{~s}$ decay time typical of $\mathrm{Q}$-bursts. The two inserts on the right reveal peaks at the Schumann resonances, suggesting that both pulses are Q-bursts. Only the second harmonic is missing in the second pulse, the reason for which is unknown at the present time. No information is available above $50 \mathrm{~Hz}$ because our experimental data sampling occurred at the rate of $100 \mathrm{~Hz}$ (hence the applicability of Nyquist's theorem) and hecause a fivepole low pass filter at $50 \mathrm{~Hz}$ is part of the electronic hardware.

These same events are also shown in Figs. 11 and 12, where the top traces are the time domain data (gamma versus time after scismic trigger) that were obtaincd by the magnetometcrs. Here we show the output of only the east-west magnetometers. The displays in the lower portions of the figures are spectrograms of the data-i.e., contours of constant power spectral density (gamma squared per $\mathrm{Hz}$ ) plotted versus time (s) and frequency $(\mathrm{Hz})$. Figure 11 shows the waveform and spectrogram in the time interval $300 \mathrm{~s}$ to $400 \mathrm{~s}$ following the explosioninduced seismic trigger, while Fig. 12 shows the same quantities in the time interval from $500 \mathrm{~s}$ to $600 \mathrm{~s}$ after the seismic trigger. We see the dominance of the two transients that we associate with $\mathrm{E}$ and $\mathrm{F}$ region responses to the explosion-induced acoustic pulse propagating vertically through the ionosphere. (Only background noise was observed in the interval from $400 \mathrm{~s}$ to $500 \mathrm{~s}$, as well as between $0 \mathrm{~s}$ and $300 \mathrm{~s}$.) 


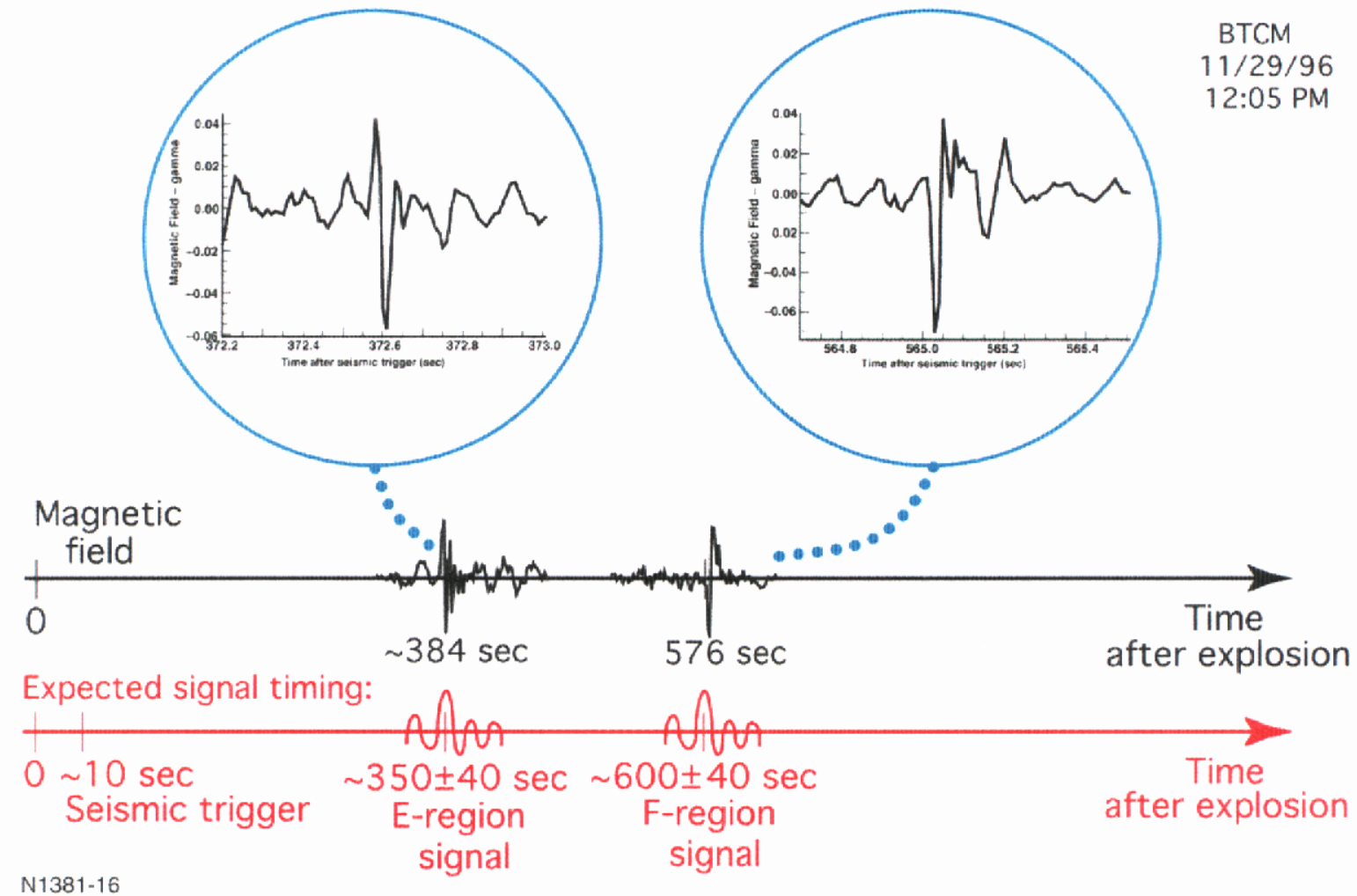

Figure 8. Timing of acoustic-induced $E$ and $F$ region signals following a $2.4 \mathrm{kT}$ explosion at Black Thunder Coal Mine on 29 November 1996 at 1205 local time. 


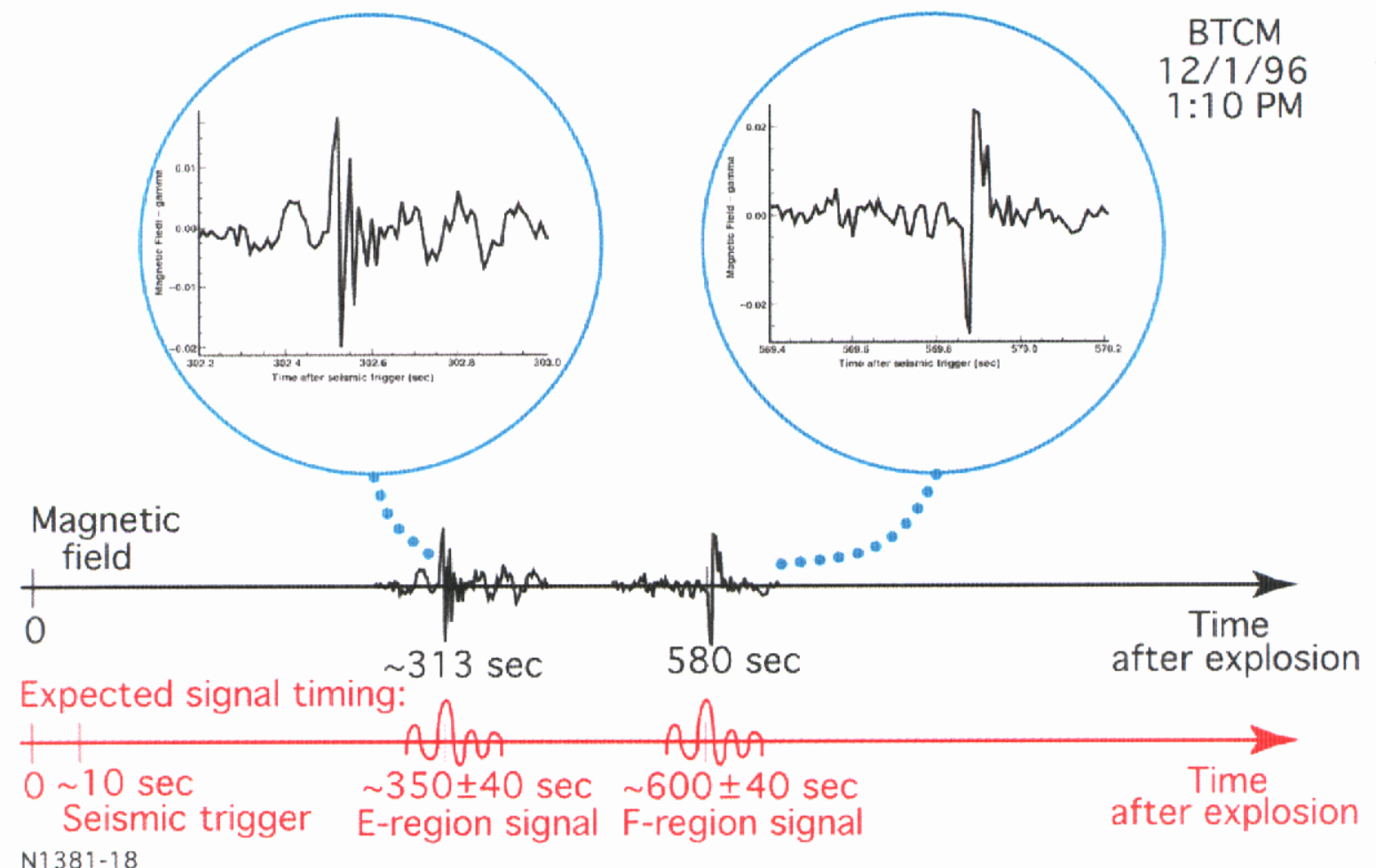

Figure 9. Timing of acoustic-induced $E$ and $F$ region signals following a $1.4 \mathrm{kT}$ explosion at Black Thunder Coal Mine on 1 December 1996 at 1310 local time. 

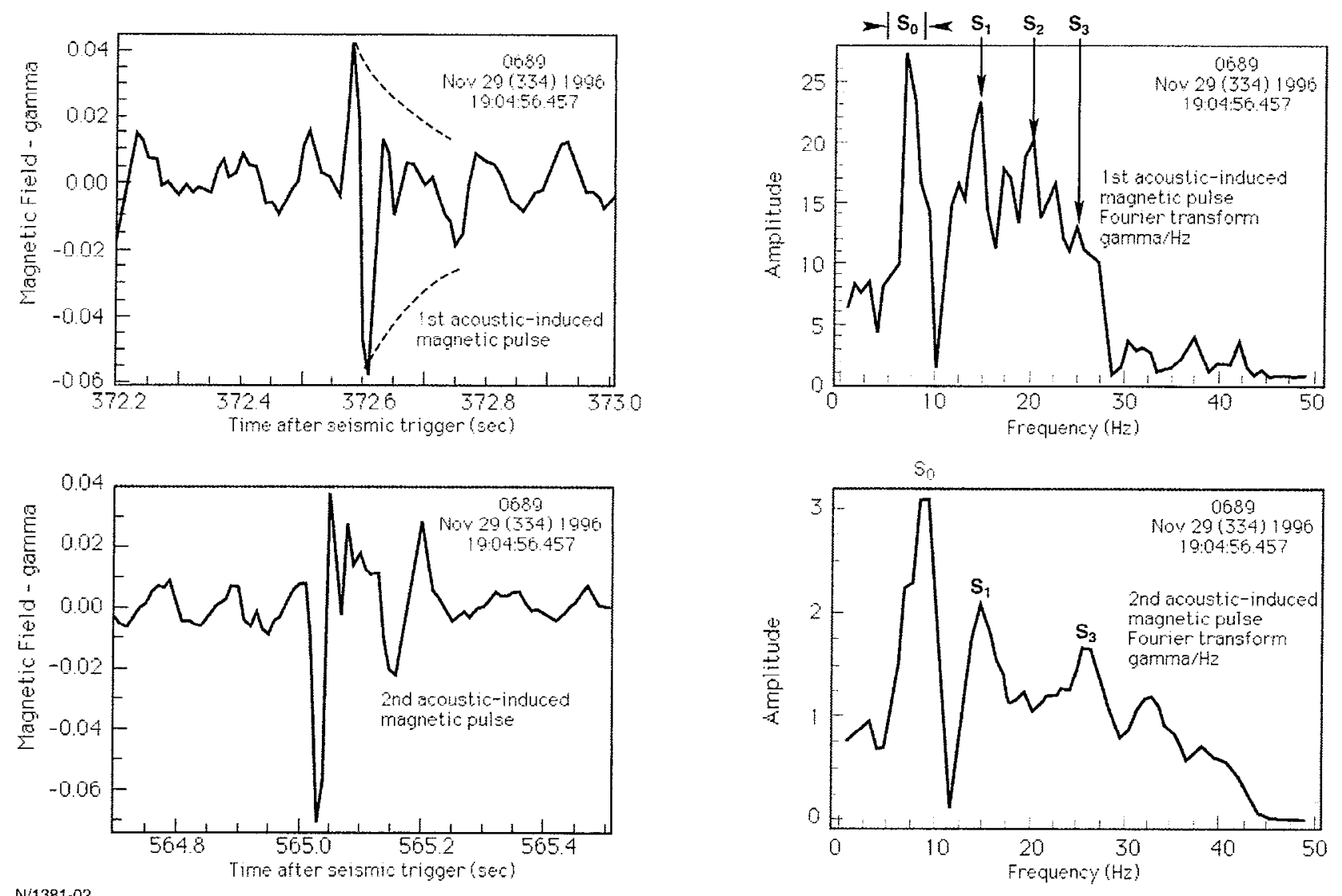

Figure 10. Time domain traces and their Fourier transforms of two pulses observed following the $2.4 \mathrm{kT}$ explosion at BTCM on 29 November 1996. The decay time of about $0.5 \mathrm{~s}$ and the dominance of the Schumann resonances are characteristic of $Q$-bursts. 

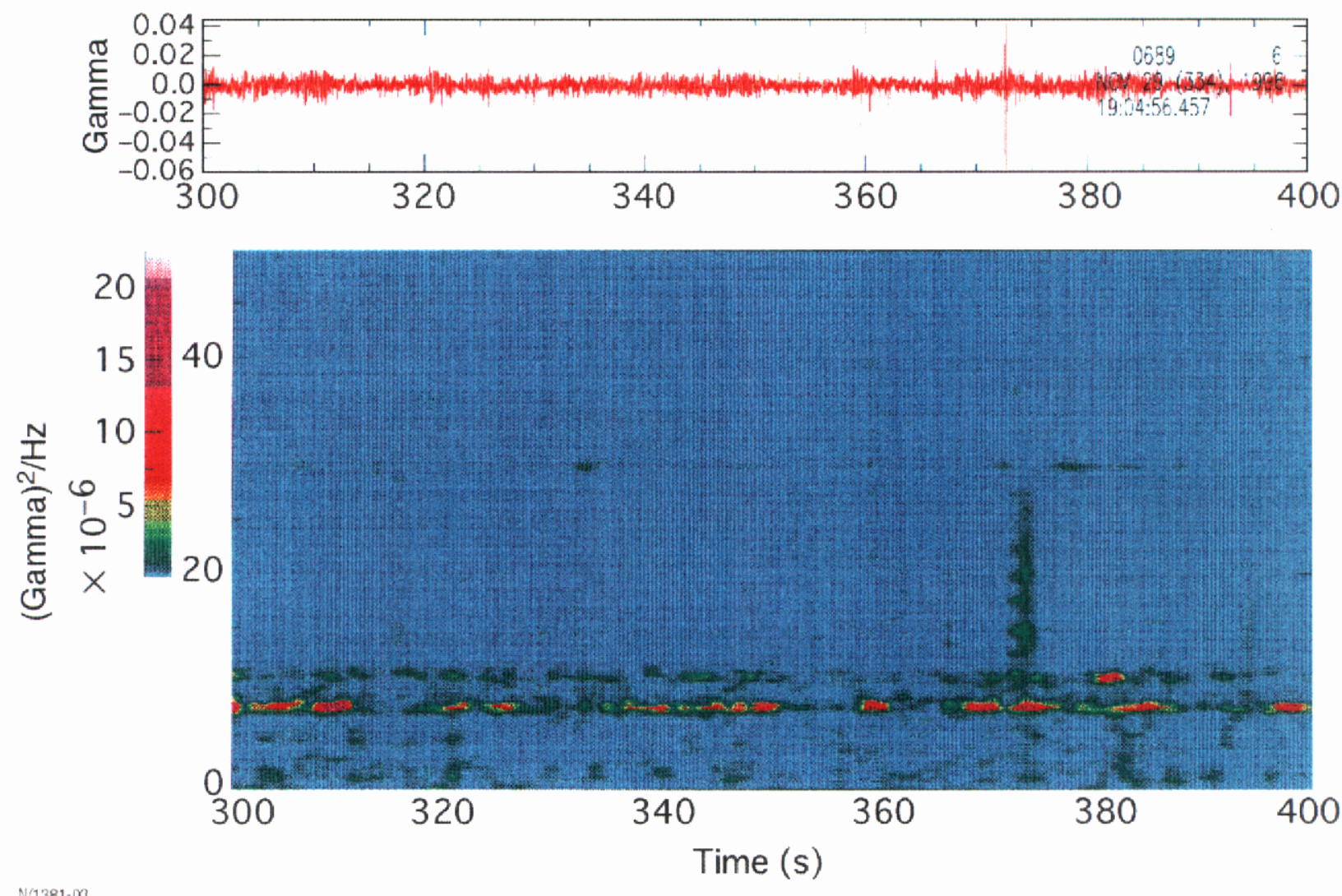

Figure 11. Waveform and spectrogram in the time interval 300 to 400 s following the explosioninduced seismic trigger associated with the $2.4 \mathrm{kT}$ explosion at BTCM on 29 November 1996. The Q-burst associated with the $N$-wave interaction in the E region is clearly evident above the noise in the time domain at $372.6 s$ and is even more enhanced in the spectrogram. 

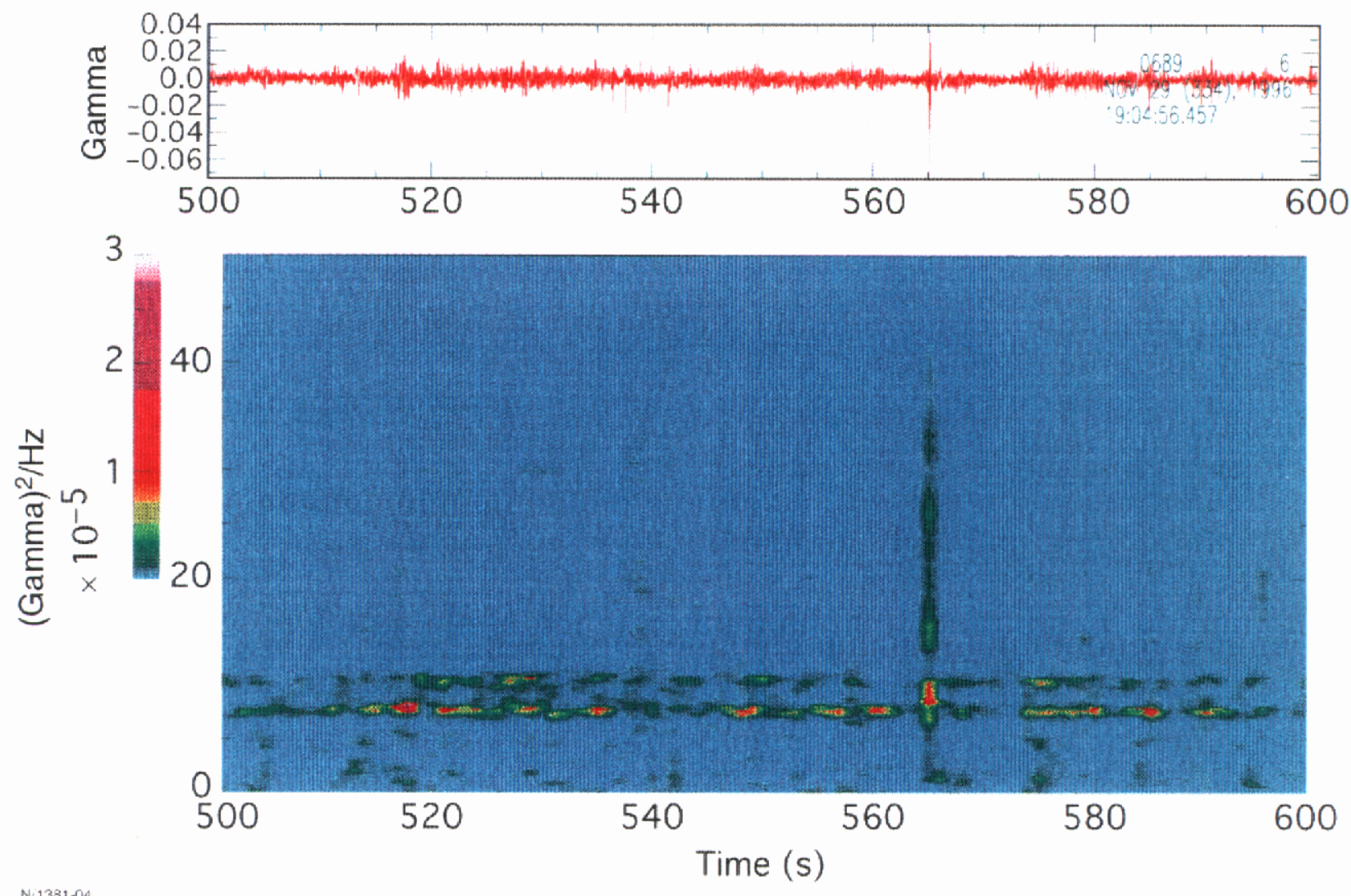

Figure 12. Waveform and spectrogram in the time interval 500 to $600 \mathrm{~s}$ following the explosioninduced seismic trigger associated with the $2.4 \mathrm{kT}$ explosion at BTCM on 29 November 1996. The $Q$-burst associated with the $N$-wave interaction in the $F$ region is clearly evident above the noise in the time domain at $565 s$ and is even more enhanced in the spectrogram. 
Given that this $2.4 \mathrm{kT}$ explosion at BTCM was almost 10 times larger than the MASSA explosion, we expect that an Alfvén soliton should have been generated in the ionosphere. Unfortunately, no satellite measurements were coordinated with the BTCM explosion to confirm this prediction. Nevertheless, we reasonably assume that such a geomagnetic disturbance was generated. These assumed Alfvén solitons would have been large enough to generate the observed Q-bursts. Although we do not have all the data to prove the contention that the Q-bursts seen in Figs. $10-12$ are caused by the $2.4 \mathrm{kT}$ explosion at BTCM, the available evidence combined with the analysis of MASSA data highly suggests that this is the case.

At this point we must ask what we expect the magnetic field perturbation to look like as a function of time. At first, we might think that the magnetic field perturbation would have the same time dependence as the $\mathrm{N}$-wave interacting with the ionosphere. This may be the case if the $\mathrm{N}$-wave entering the $\mathrm{E}$ region is sufficiently small that a linear interaction of the $\mathrm{N}$-wave and the ionosphere occurs. In most cases, however, we expect the $\mathrm{N}$-wave to be a large amplitude acoustic wave at this altitude. Then a nonlinear interaction would occur and we might expect that the magnetic field disturbance would depend on the derivative of the $\mathrm{N}$-wave. In the case of an $\mathrm{N}$-wave with a very steep front, the derivative will be a large narrow square wave-almost a delta function-followed by a small negative square wave and then by a small positive square wave. Then the magnetic field perturbation may be a single large narrow pulse in time followed by two much smaller pulses that may fall below the background noise level. This picture appears consistent with experimental results and theory presented by Stubbe et al. (1982) who measured an ELF pulse generated when an HF pulse interacting with the ionosphere was switched on and off. The Fourier transform of a square wave is a sync function. The square of the magnitude of this transform integrated over a selected frequency band is the energy per $\mathrm{Hz}$ contained in that frequency band. Contours of constant energy per $\mathrm{Hz}$ are plotted in a sonogram as a function of frequency and time. Perhaps the above interpretation is what we need for the dominant event that appears in each of the sonograms provided in Figs. 11 and 12.

On 19 December 1996, our magnetometers were triggered by two unannounced explosions separated in time by $4 \mathrm{~min} 14 \mathrm{~s}$ (Fig. 13)—which was determined from our scismometcr data. By "unannounced" we mcan that the explosions occurred at mining 


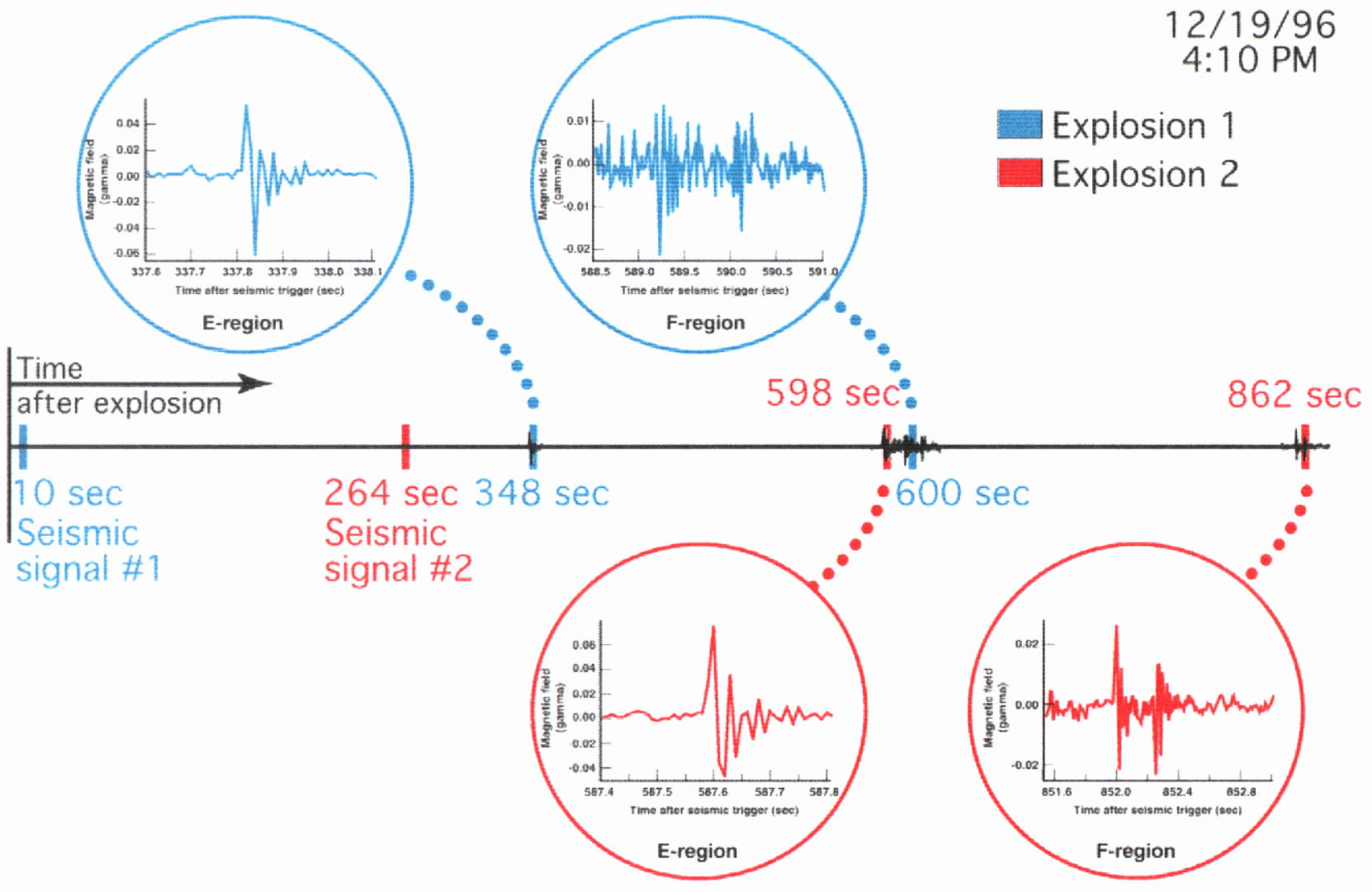

Figure 13. E and $\mathrm{F}$ region signals apparently associated with two unannounced explosions that were separated in time by $4 \mathrm{~min} 14 \mathrm{~s}$. 
sites other than BTCM. We had not been coordinating with any of the other mining operations regarding the scheduling of their explosions-partly because their explosions were generally not as large as those at BTCM and partly because of the logistics involved in communicating with so many mine operations. We knew about their occurrences only by detecting them with our seismometers. Here (Fig. 13) we see four separate signals with times of occurrence consistent with generation by the acoustic waves, from each of the two explosions, propagating through the $\mathrm{E}$ and $\mathrm{F}$ regions of the ionosphere. The $\mathrm{E}$ region interactions occurred at $348 \mathrm{~s}$ (approximately $118 \mathrm{~km}$ altitude) after the first explosion and $334 \mathrm{~s}$ (approximately $114 \mathrm{~km}$ altitude) after the second. The F region interactions occurred at $600 \mathrm{~s}$ (approximately $204 \mathrm{~km}$ altitude) after the first explosion and $598 \mathrm{~s}$ (approximately $203 \mathrm{~km}$ altitude) after the second. The time interval between the two pulses associated with the first explosion is $252 \mathrm{~s}$ while that associated with the second explosion was $264 \mathrm{~s}-$-a difference of $12 \mathrm{~s}$ in the two intervals corresponds to a difference in altitude of only about $4 \mathrm{~km}$. Unfortunately, the yields of these two explosions are unknown. The times of occurrences of the four pulses are highly suggestive of cause and effect.

An interesting phenomenon recorded by both observatories is shown in Fig. 14, which is a plot of the responses at both sites of the vertical magnetometers in volts versus time following the seismic triggers generated by an explosion with a yield of $0.490 \mathrm{kT}$ at BTCM on 11 January 1998 at 2205 GMT (1505 MDT). The top trace in the top figure was recorded at the observatory closest to the explosion (observatory \#1), and the bottom trace in the top figure was recorded at the observatory farthest from the explosion (observatory \#2). Although the traces look somewhat complex due to the presence of noise, we make particular note of the first large spike at each site. (The other spikes appear to be noise and are not of any particular significance.) These signals are shown on expanded time scales in the two lower figures. Their waveforms are quite similar.

Taking into account the actual location of the explosion $\left(43^{0} 39^{\prime} 50^{\prime \prime} \mathrm{N}, 105^{0} 17^{\prime} 07^{\prime \prime} \mathrm{W}\right)$, we obtained distances from the explosion to the two sites as $55.0 \mathrm{~km}$ and $69.2 \mathrm{~km}$. Considering the speed of propagation of the seismic P-wave $(\sim 5 \mathrm{~km} / \mathrm{s})$, we calculated the delays in the seismic triggers at the two sites as $11.0 \mathrm{~s}$ and $13.8 \mathrm{~s}$, respectively. Adding these delay times to the times of occurrences of the pulses shown in Fig. 14 and dividing into the distances to the sites, we obtained $310 \mathrm{~m} / \mathrm{s}$ and $320 \mathrm{~m} / \mathrm{s}$, respectively, for the speeds at which the signals 

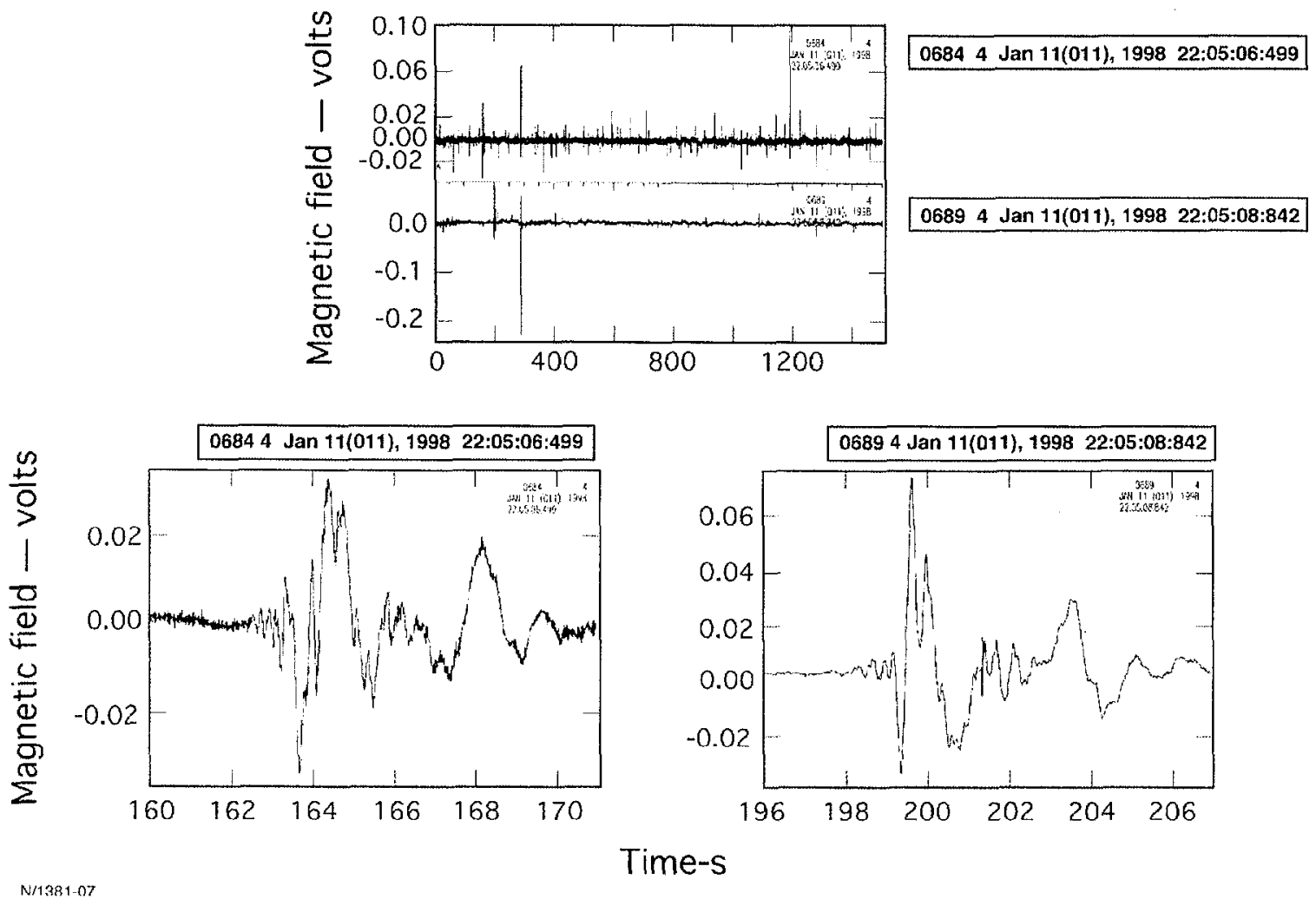

N/1381 07

Figure 14. Ground motion caused by direct explosion-induced acoustic signal shakes the magnetometers and generates a magnetic signal. Calculated speed of propagation for the observed arrival times was very close to the ambient speed of sound in air. 
propagate to the closest (Observatory \#1) and farthest (Observatory \#2) observatories, respectively. The low end of our temperature measurement at Observatory \#2 was -14 degrees centigrade $(\mathrm{C})$, or 259 degrees Kelvin $(\mathrm{K})$. The speed of sound $(\mathrm{m} / \mathrm{s})$ in dry air is given approximately by $20.1 \times(\mathrm{T})^{0.5}$, where $\mathrm{T}$ is air temperature in degrees $\mathrm{K}$. The calculated speed of sound at Observatory \#2 is therefore $323 \mathrm{~m} / \mathrm{s}$, which is in reasonable agreement with that of the observed signal. We see that the signals appear to have propagated directly through the air from the explosion site to the observatories.

We measured this acoustic disturbance on the vertical magnetometer, which can detect change of $10^{-7}$ degrees or more from the vertical (Conti, 1998). The vertical magnetometer is $1.42 \mathrm{~m}$ long. Movement through this angle would correspond to a horizontal movement of $1.75 \times 10^{-9} \mathrm{~m}$, or equivalently, 1.75 nanometers. We see that these signals apparently propagated in air directly along the ground surface at the speed of sound and subsequently induced magnetic signals in the magnetometers from induced ground motion.

We first thought that this disturbance could be a Lamb wave (Lamb, 1932; Beer, 1974; Gossard and Hooke, 1975; Garrett, 1969; Golitsyn, 1965; Bretherton, 1969). A Lamb wave propagates nondispersively at the speed of sound along the ground in an isothermal atmosphere, vibrates only in the horizontal direction and is evanescent in the vertical direction. Horizontal oscillations occupy the whole vertical thickness of the atmosphere and the wave energy density decays exponentially with increasing altitude. Lamb waves have often been observed following large surface and atmospheric explosions. In general, however, they are observed only in the far field rather than in the near field of an explosion. For example, a $1 \mathrm{~Hz}$ explosion-induced disturbance will develop into a Lamb wave only at distances beyond about $200 \mathrm{~km}$ (ReVelle, 1998). A $10 \mathrm{~Hz}$ signal requires about $1000 \mathrm{~km}$ to develop into a Lamb wave. Considering that our observatories are much closer than these distances to the explosion, we conclude that we are apparently observing the effect of an acoustic wave propagating directly along the ground from the explosion. The magnetometers are very sensitive tiltmeters that perform as acoustic transducers.

The signal recorded at the farthest site has a peak amplitude almost three times larger than that recorded at the closest site. Part of this enhancement could be due to the fact that the farthest site is higher in altitude than the closest site, and that the amplitude of the acoustic disturbance increases exponentially with increasing altitudes, at least at altitudes below approximately $90 \mathrm{~km}$. The difference in altitude between the two sites, however, is only about 
$43 \mathrm{~m}$. This difference is insufficient to explain an enhancement factor of three. Another possible explanation is that the phased constructive and destructive action of acoustic signals arriving from different parts of the extended explosive source produces different combined acoustic signal amplitudes at the two observatories. It is also likely that the soils at the two sites are compacted differently around the magnetometers, thus determining how much movement can be induced in the magnetometers by the ground motion.

Given that acoustic waves are nondispersive at distances of concern here, we suggest that the waveforms depicted in the bottom two graphs of Fig. 14 may serve as starting waveforms for modeling the propagation of acoustic disturbances from distances near an explosion out to greater lateral distances from the explosion.

\section{Ultra Low Frequency Phenomena}

We have argued that Q-bursts can be generated by Alfvén waves (particularly Alfvén solitons) excited by explosion-induced acoustic disturbances propagating upward through the ionosphere. If lightning as well as Alfvén waves (or hydromagnetic waves), however, can excite Q-bursts, then we need some method by which to discriminate the various origins of Q-bursts. More specifically, we must be able to distinguish Q-bursts excited by naturally occurring lightning and Alfvén waves from those excited by explosion-induced Alfvén waves. One possible approach to this problem is to analyze late-time geomagnetic phenomena associated with explosions.

We first evaluate the background magnetic noise at low frequencies $(\sim 0.01 \mathrm{~Hz}-0.1 \mathrm{~Hz})$, as shown in the two spectrograms in the top row in Fig. 15. (This frequency band is part of a broader band called ultra low frequency [ULF], which is defined as frequencies in the range of $3 \mathrm{~Hz}$ and lower [Matushita and Campbell, 1967].) These data were obtained in November 1997 by having the magnetometers record continuously during one twenty-four hour period. These spectrograms depict analyses of data recorded by the north-south magnetometer (on the top left) and by the east-west magnetometer (on the top right), both located at observatory \#2. (The vertical magnetometer was not working during this time period.) The time axes extend from $15,000 \mathrm{~s}$ to $15,800 \mathrm{~s}$, where zero corresponds to 0800 hours LT-i.e., Mountain Standard Time (MST). Therefore, $15,000 \mathrm{~s}$ correspond to $1210 \mathrm{MST}$. The top two figures each contain $800 \mathrm{~s}$ of 

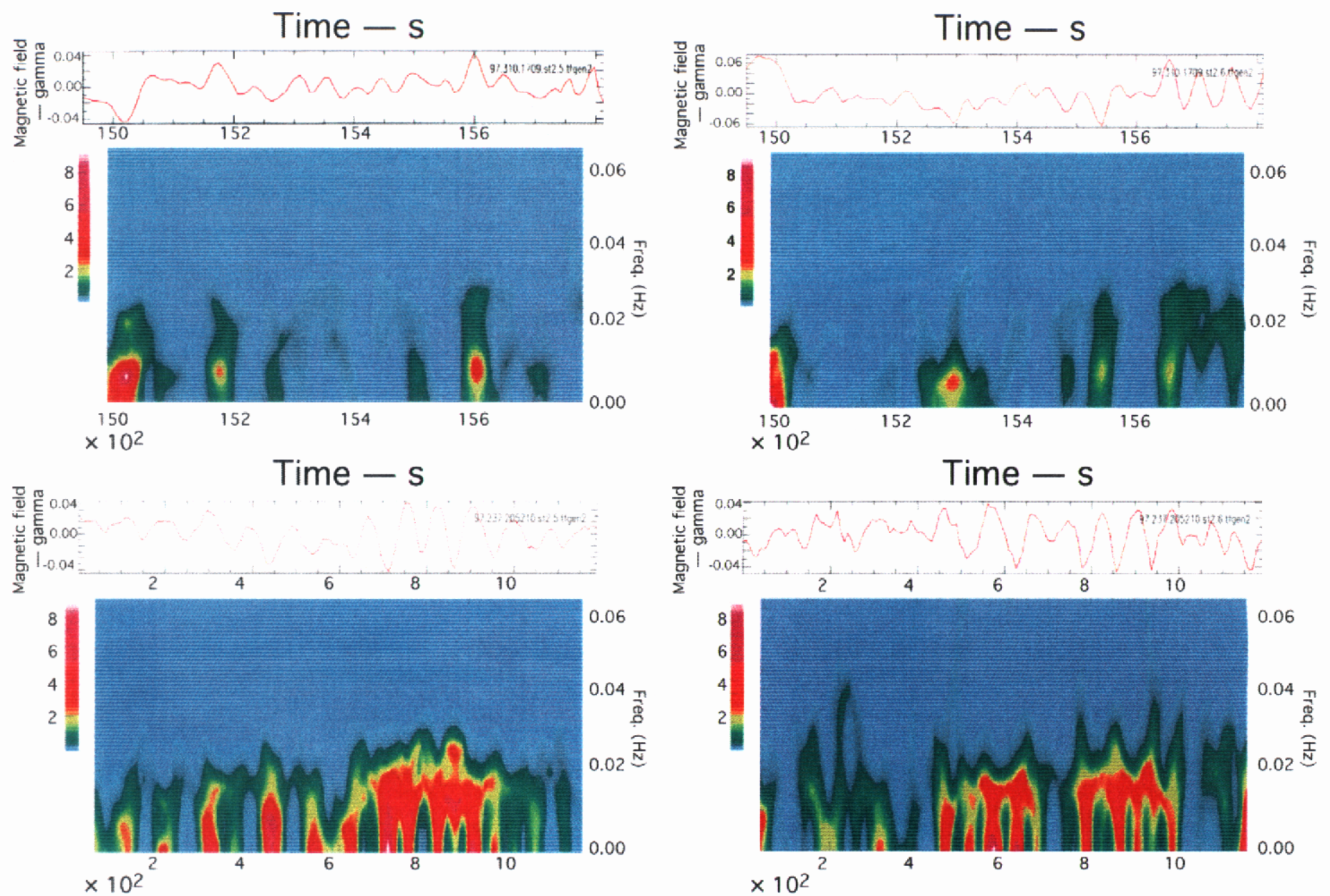
N/1381-06

Figure 15. Comparison of spectrograms of background data (top two spectrograms) with data obtained from a $1.52 \mathrm{kT}$ explosion (bottom two spectrograms). The spectrograms are plots of contours of constant spectral intensity (gamma squared per $\mathrm{Hz}$ ) as a function of frequency $(\mathrm{Hz}$-vertical scale) and time ( $\mathrm{s}$ - horizontal scale). Intensity appears to be enhanced above background after explosion. The time domain waveform is displayed above each spectrogram. The origin of the time axis coincides with the seismic trigger. 
data. This time interval was seismically quiet-i.e., no seismic triggers were received by oúr seismometers. The bottom two graphs are spectrograms for data recorded at observatory \#2 by the north-south magnetometer (on the bottom left) and by the east-west magnetometer (on the bottom right) during the time immediately following a seismic trigger due to a $1.52 \mathrm{kT}$ explosion at BTCM on 25 August 1997. These spectrograms extend from $100 \mathrm{~s}$ to $1200 \mathrm{~s}$ following the seismic trigger. Comparison of the two sets of sonograms reveals that there is enhanced activity at these frequencies immediately following cxplosions-assuming that background is not a strong function of season.

An interesting phenomenon was recorded $900 \mathrm{~s}$ after a $1.21 \mathrm{kT}$ explosion at BTCM on 25 June 1997 at 1140 LT as seen in Fig. 16. The top two traces were recorded by the north-south magnetometers at observatories \#2 and \#1, respectively. The bottom two traces were recorded by the east-west magnetometers at observatories \#2 and \#1, respectively. We see that there is excellent correlation between the data recorded at the two sites. This indicates that the phenomenon is not local, but extends over distances greater than $14 \mathrm{~km}-\mathrm{i}$.e., the distance of separation of the two observatories. In other words, the signal can not be caused by automotive traffic, trains, animals, local machinery, power lines, or other magnetic sources that are near to one site but not to the other. We also observe that the signal is clearly dispersive, and that it lasts for approximately $200 \mathrm{~s}$. The delay of over $900 \mathrm{~s}$ suggests that its origin is probably in the F region of the ionosphere at an altitude of approximately $300 \mathrm{~km}$-i.e., close to the $\mathrm{F}$ region maximum in the electron density profile.

In actuality, the traces nearly fit the description of a category of continuous pulsations (pc) called pc 2-3 geomagnetic micropulsations (Matsushita and Campbell, 1967, vol. II, p. 876). Such pulsations have periods in the range of $5 \mathrm{~s}$ to $30 \mathrm{~s}$ with amplitudes usually less than 0.5 gamma. (The voltages in Fig.16 may be converted to gammas by dividing by approximately 0.3 volts per gamma.) The periods have a diurnal variation that peaks at $20 \mathrm{~s}$ to $30 \mathrm{~s}$ at midday and falls to $5 \mathrm{~s}$ to $10 \mathrm{~s}$ at night. Pe 2-3 pulsations are typically daytime phenomena and maximize their activity near midday. In addition, they are generally associated with $\mathrm{F}$ region electron density variations. Many investigators have attempted to associate pc 2-3 pulsations with $F$ region current systems. Although this description nearly fits the traces in Fig. 16, we must not rush to a hasty conclusion. 


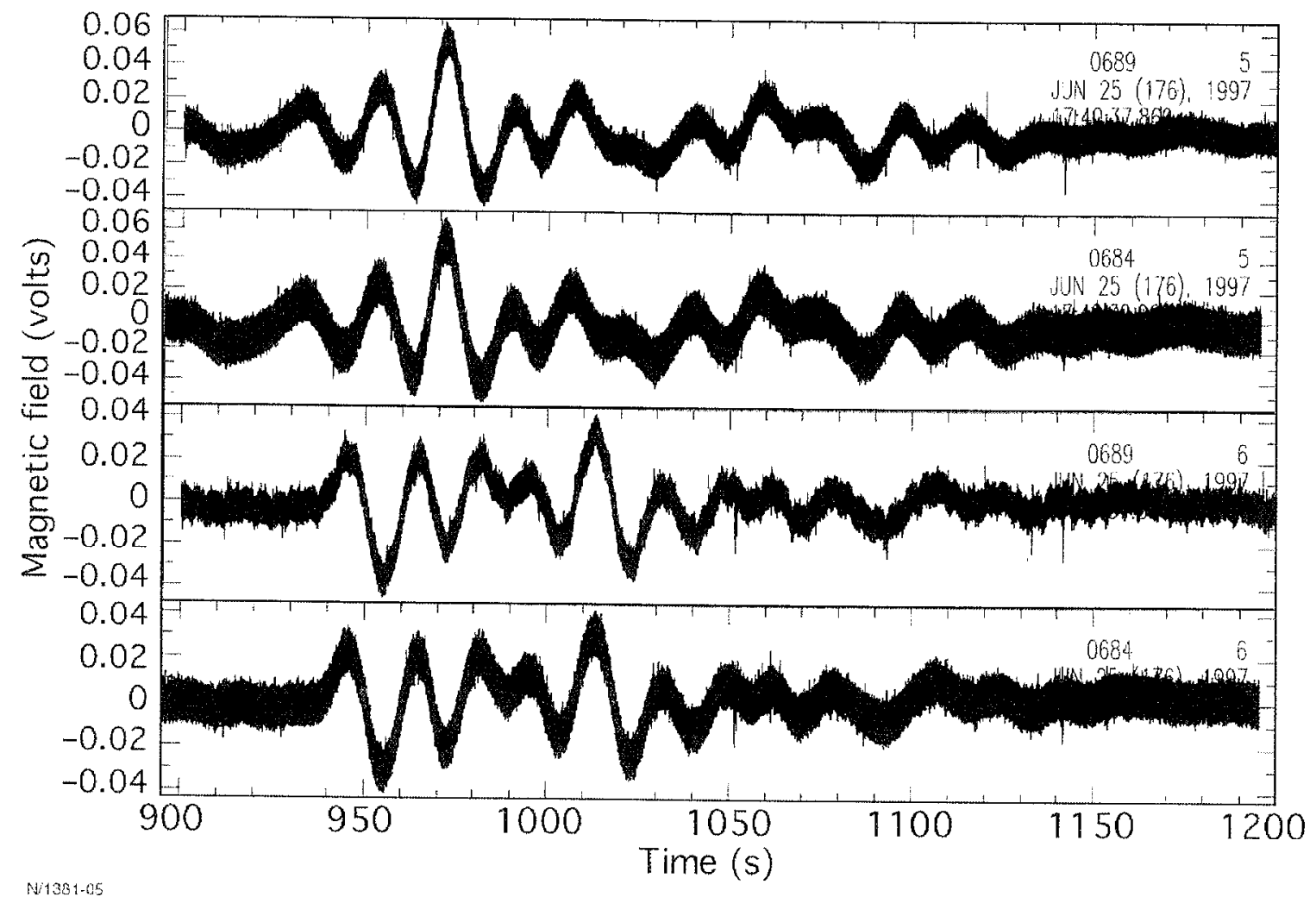

Figure 16. Inter-site comparison of north-south and east-west magnetometer responses following an explosion with yield of $1.21 \mathrm{kT}$. The top two traces are the north-south responses for observatories \#2 and \#1, respectively. The bottom two traces are the east-west responses for observatories \#2 and \#1, respectively. The signals look the same at both sites. They also look similar to pc 2-3 micropulsations, but they appear to be explosion-induced in the F region. 
The fact that this disturbance occurs close to $950 \mathrm{~s}$ after the explosion is suggestive of cause and effect, because it corresponds to the approximate time required for the acoustic pulse to reach the peak of the electron density in the $F$ region and to generate electron density perturbations. In addition, we expect the period of the acoustic wave to be approximately $20 \mathrm{~s}$ at this altitude (Warshaw and Dubois, 1981). Also, the fact that this observed waveform had a rather sudden onset suggests that it is not of natural origin, since naturally occurring pc 2-3 pulsations are continuous in time-hence the nomenclature pc for "pulsation continuous." It is possible that this observed phenomenon is the result of modulation of a portion of a pc 2-3 wave train by the acoustic wave from the explosion. More research on this matter is warranted.

Another approach to analyzing the data is to examine the polarization of the measured horizontal magnetic fields. An example is shown in Fig. 17. Here we analyze data obtained at observatory \#1 (also identified as station \#4 for historical reasons) following an explosion of $0.490 \mathrm{kT}$ at BTCM on 11 January 1998 at 1457 LT. A fifty second data segment of the northsouth magnetic field values is plotted against east-west magnetic field values for three different times following the seismic trigger. (This is a rather crude way of analyzing polarization. A more sophisticated approach would be to follow Sentman, 1989; however, available time and funding did not permit us this luxury.) We note that at early time $(250 \mathrm{~s}-300 \mathrm{~s})$ the polarization appears to be random. At late time $(>850 \mathrm{~s}$ ) we see that an elliptical polarization emerges. Analyses of data from observatories \#1 and \#2 obtained following a $0.659 \mathrm{kT}$ explosion at BTCM on 13 February 1998 at 1353 LT are shown in Figs. 18 and 19, respectively. The same conclusions are drawn from these latter data. A comparison is now made in Fig. 20 with the same type of analysis of the previously mentioned background data obtained in November 1997. In this latter case we note that the polarization is always random and that no elliptical polarization ever appears. The conclusion we draw here for a limited amount of data is that the horizontal polarization of the magnetic field recorded at late time $(\sim 800 \mathrm{~s}$ or later) following an explosion becomes elliptically polarized after having been randomly polarized at earlier times. This feature may offer a means by which we might discriminate a Q-burst excited by an explosion-induced Alfvén wave from one excited by a naturally occurring Alfvén wave or by lightning. Obviously more research is required to confirm or falsify this hypothesis. 


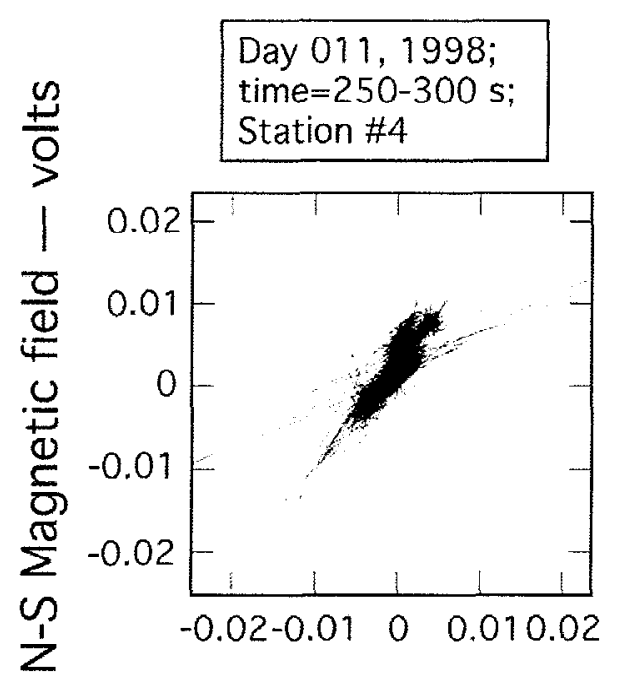

N/1381-09
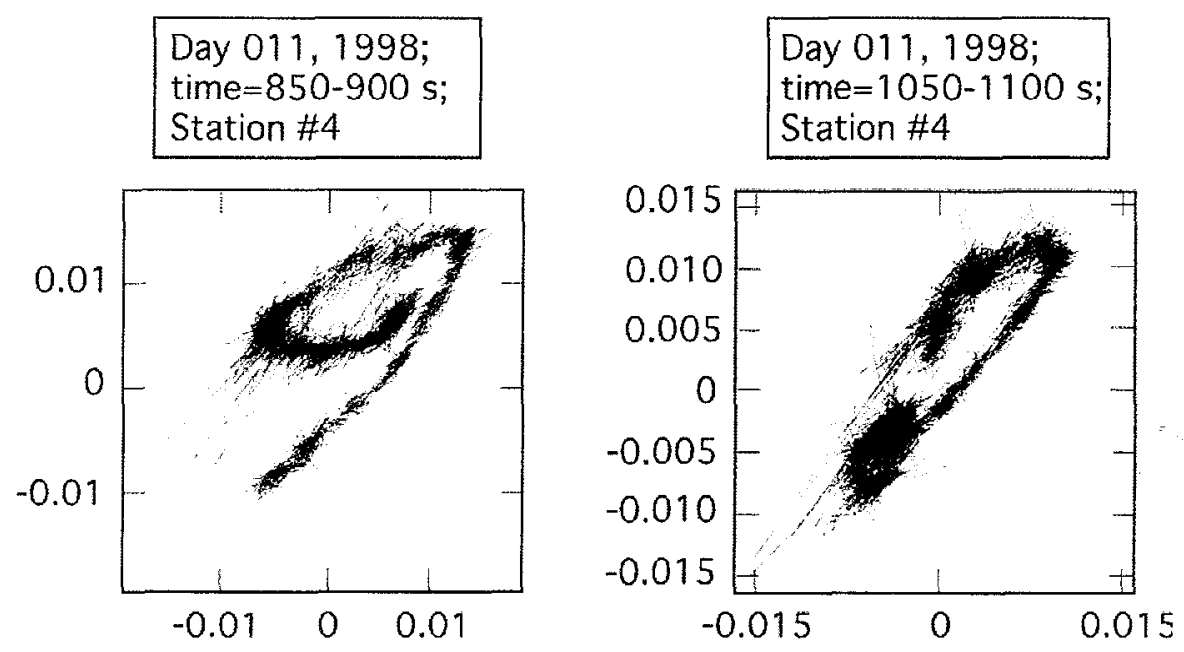

E-W Magnetic field - volts

Figure 17. Horizontal polarization of early and late time data recorded at observatory \#1 following a $0.490 \mathrm{kT}$ explosion on 11 January 1998. Fifty seconds of north-south magnetometer data are plotted against east-west data. Random polarization is observed at early time while elliptical polarization is observed at late time. 


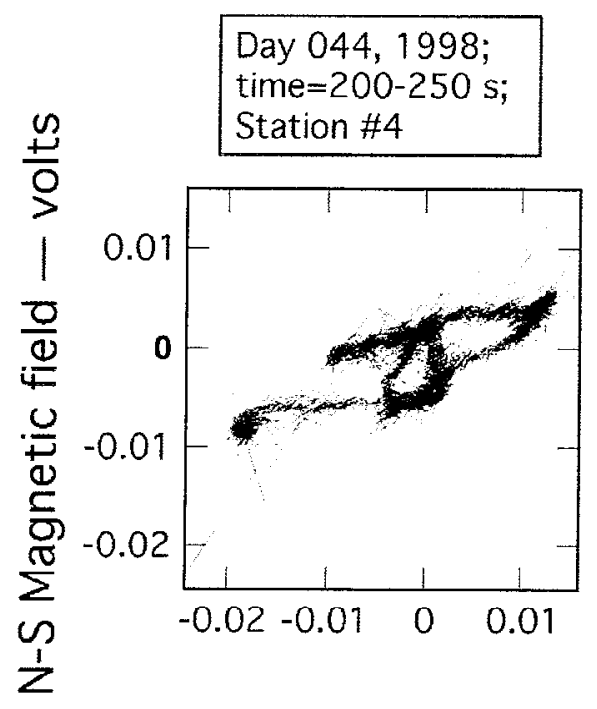

N/1381-11
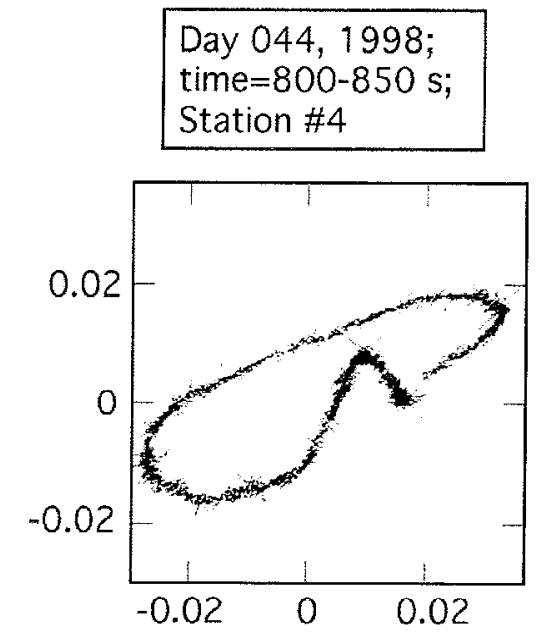

E-W Magnetic field - volts
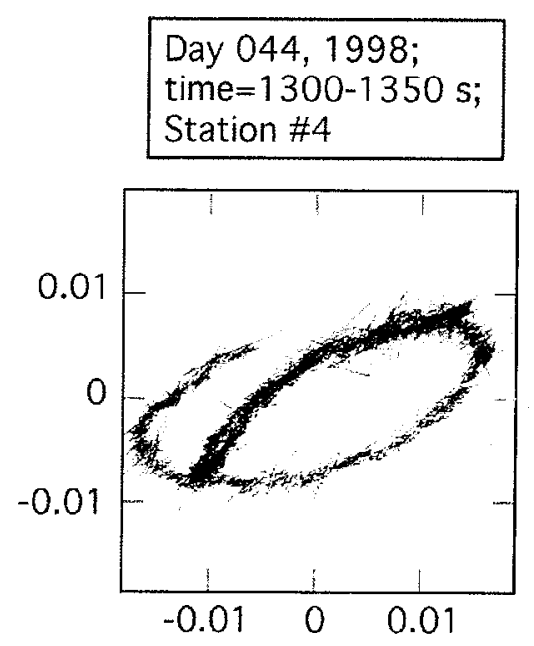

0.010 .01

Figure 18. Horizontal polarization of early and late time data recorded at observatory \#1 following a $0.659 \mathrm{kT}$ explosion on 13 February 1998. Fifty seconds of north-south magnetometer data are plotted against east-west data. Random polarization is observed at early time while elliptical polarization is observed at late time. 


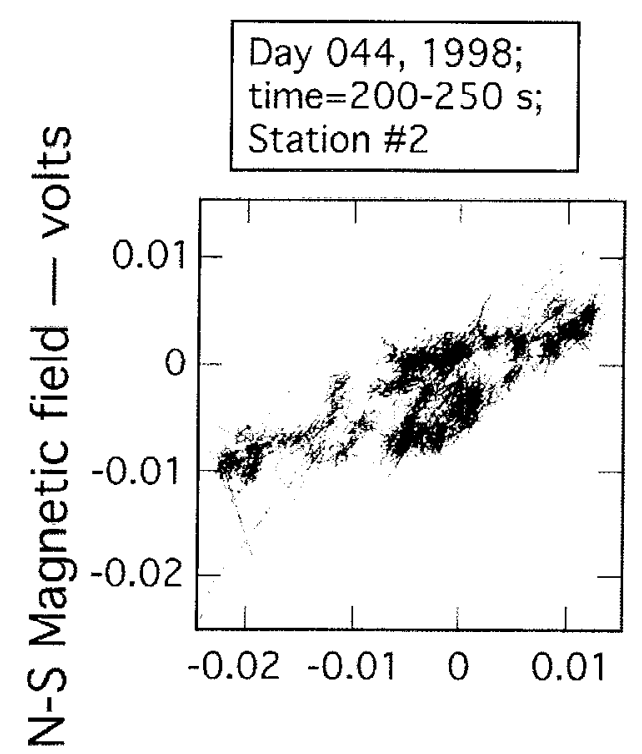

N/1381-10
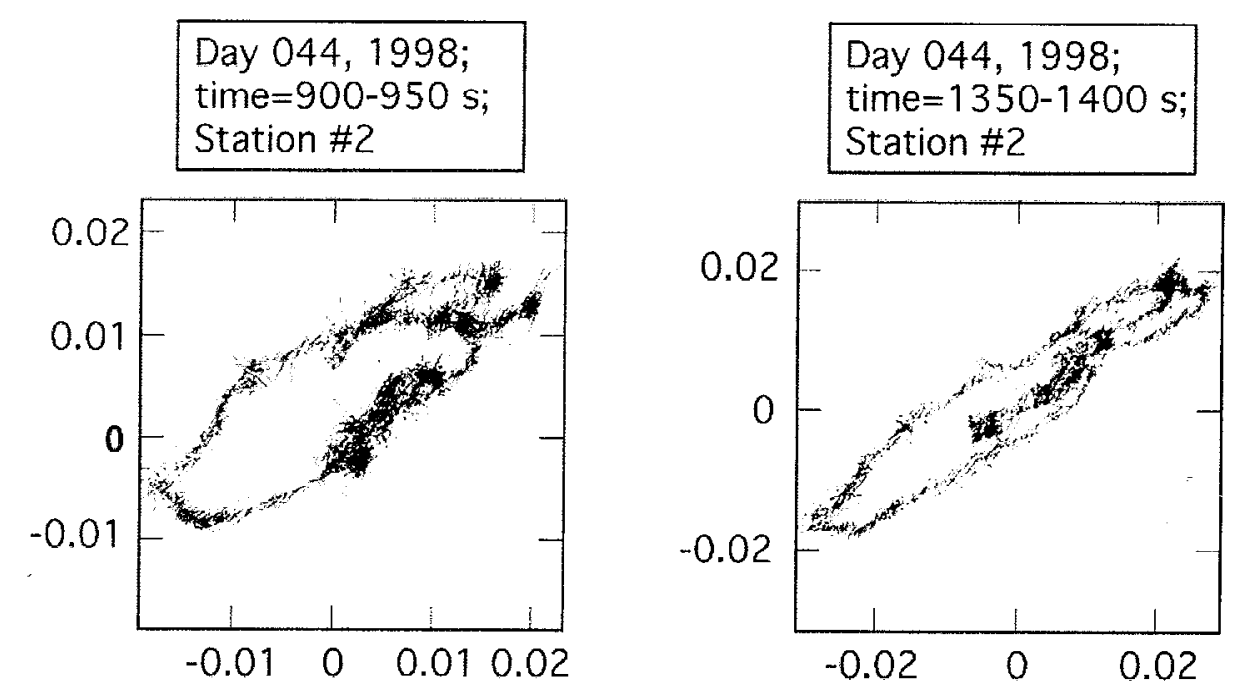

E-W Magnetic field - volts

Figure 19. Horizontal polarization of early and late time data recorded at observatory \#2 following a $0.659 \mathrm{kT}$ explosion on 13 February 1998. Fifty seconds of north-south magnetometer data are plotted against east-west data. Random polarization is observed at early time while elliptical polarization is observed at late time. 


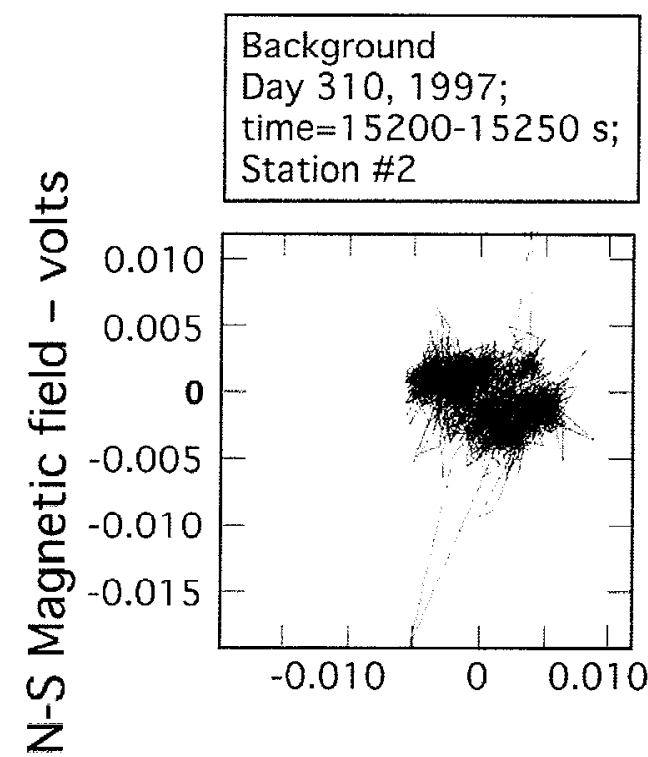

N/1381-12

\section{Background}

Day 310, 1997;

time $=15400-15450 \mathrm{~s}$;

Station \#2

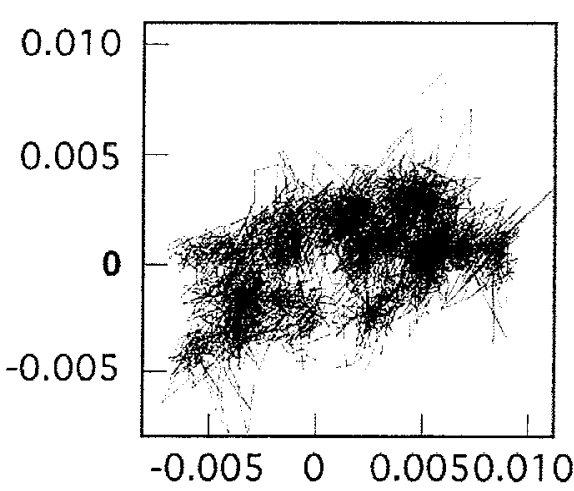

E-W Magnetic field - volts
Background

Day 310, 1997;

time=15600-15650 s;

Station $\# 2$

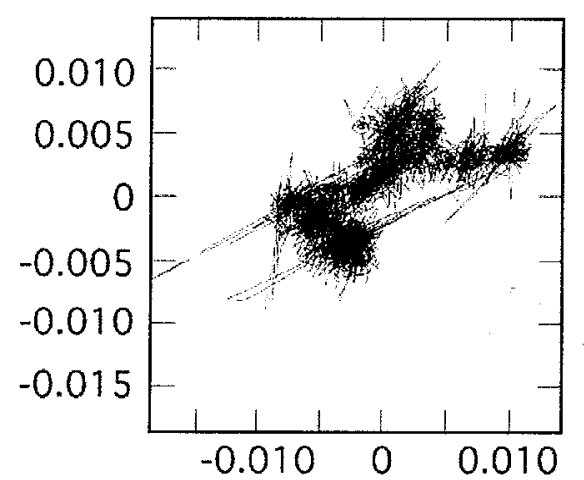

Figure 20. Horizontal polarization observed for three different fifty second time frames at observatory \#2 on 24 November 1997 during a time period when no seismic activity occurred-i.e., we received no seismic triggers from explosions or other seismic activity. 
In addition to detecting explosive events, we desire to locate them as well. Some critics contend that ULF signals can not be used to locate the sources of explosion-induced geomagnetic disturbances and that fast rising transients (at least at ELF or higher frequencies) are required for this task. This contention runs contrary to historical scientific practice. For example, meteorologists for as long as 50 years have routinely tracked the motion of tornadoes by analyzing the polarization of tornado-induced infrasound-frequencies below the audible threshold of approximately $20 \mathrm{~Hz}$. (A similar method recently reported for analyzing the polarization of seismic records is provided by Lilly and Park [1995].) Other methods that could possibly be used for locating magnetic sources include directional analysis (Chetaev, 1978), triangulation (Frazer and Wawrzyniak, 1978) and dispersion and group delay (Feygin et al., 1979). A spectral method advanced by Nickolaenko and Kudintseva (1994) for locating ELF transients may also have applicability here.

\section{Conclusions}

Magnetic measurements were obtained in the frequency range $0.01 \mathrm{~Hz}-50 \mathrm{~Hz}$ with three mutually orthogonal induction magnetometers at each of two separate observatories located at distances of $50 \mathrm{~km}$ and $64 \mathrm{~km}$ geomagnetically north of the Black Thunder Coal Mine (BTCM) open-pit coal mine operation near Gillette, Wyoming. The explosions at BTCM were ripplefired and had yields ranging from one to three kT TNT equivalent. These measurements contained transients that had times of occurrence that suggested they were generated in the $\mathrm{E}$ and F regions of the ionosphere by upward propagating explosion-induced acoustic waves. They were also dominated in the frequency domain by the Schumann resonances (Schumann, 1952; Sentman, 1995). In addition, the transients were large single events with decay times of about $0.5 \mathrm{~s}$, which further suggested they were Q-bursts (Ogawa et al.. 1967; Sentman, 1995).

According to results of studies (Abbas, 1968; Greifinger and Greifinger, 1965; Shaeffer, 1971) of transmission of hydromagnetic waves through the ionosphere into the atmosphere, the magnitude of the energy flux contained in the Alfvén soliton (Gal'perin et al. 1986; Pokhotelov et al., 1994) observed following the MASSA experiment was sufficient to penetrate the ionosphere and excite a Q-burst within the earth-ionosphere waveguide. (No such Q-burst was reported during the MASSA experiment apparently because no one was looking for it.) A similar chain of events must have occurred following the explosions reported above that occurred at the BTCM, given that these explosions were much larger than MASSA. Based on reported sighting of an Alfvén soliton following the MASSA event, and given the sizes of the BTCM explosions reported above, we surmise that Alfvén solitons must have been excited by collisional interaction of the explosion-induced vertically propagating acoustic disturbance with 
the $\mathrm{E}$ and $\mathrm{F}$ regions of the ionosphere. Their energy fluxes would have been sufficient to excite the observed Q-bursts reported above. (See Appendices A and B.) This appears to be the first indirect evidence confirming the prediction by Abbas (1968).

Our magnetic measurements also reveal the occurrence of late time (>800 s) ULF signals that appear to be generated in the upper $F$ region $(>300 \mathrm{~km})$. The magnitudes and waveforms of these signals are essentially identical at each of the two magnetic observatories, further indicating that the signals are not locally excited-i.e., they can not be due to cars, trains, or local machinery-and that the magnetic equipment is operating correctly at each of the two sites. They are also very similar to pc 2-3 micropulsations, which have their origin in the upper F region. However, their occurrences in time relative to the explosions and their sudden onset, rather than occurring as part of a continuous train, suggest that the more likely causation is the explosions. We further suggest that the occurrence of these late time signals may be useful in helping to discriminate which Q-bursts are associated with lightning or with naturally occurring Alfvén waves and which ones are associated with explosion-induced hydromagnetic (or Alfvén) waves.

On onc occasion we obscrved magnetic signals that were delayed in arrival at the two sites by times determined by propagation of a disturbance at the speed of sound. We interpret this phenomenon as the arrival of an acoustic disturbance propagating in air directly along the ground surface from the explosion to the magnetic observatories. The vertical magnetometers, acting as tiltmeters, sensed the horizontal motion of the ground induced by the arriving acoustic waves. We suggest that the magnetic waveforms induced by the acoustic signal may be used in modeling efforts as a starting condition to effect the solution for propagation of the acoustic wave to even greater lateral distances from a ripple-fired explosion.

Further experimental and theoretical work are required to improve confidence in these conclusions because limited experimental data were used to draw these conclusions. Moreover, the above findings will not be practically useful for monitoring purposes unless we can establish similar findings for distances far from the explosions-i.e., on the order of $1000 \mathrm{~km}$ or more. 


\section{Acknowledgment}

This research is funded by the Laboratory Directed Research and Development (LDRD) Program at Lawrence Livermore National Laboratory (LLNL). The LDRD Program is mandated by Congress to fund director-initiated, long-term research and development (R\&D) projects in support of the DOE and national laboratories mission areas. The Director's Office LDRD Program at LLNL funds creative and innovative R\&D to ensure the scientific vitality of the Laboratory in mission-related scientific disciplines.

The authors would like to thank Hans Kruger, Fred Followill, and Al Kaufman of Lawrence Livermore National Laboratory for their contributions to the success of this project. We especially thank Hans Kruger for his continued moral support throughout the conduct of the project and for many penetrating insights to various theoretical and experimental aspects of the work. We thank Fred Followill for his willingness to listen to arguments and offer advice on matters related to experimental methods. We thank Al Kaufman for his assistance with the mathematics in Appendix B. The authors express special gratitude to Professor Mikhail B. Gokhberg, Institute of Physics of the Earth, Moscow, Russia, for his extended dialogue on matters pertaining to this project and for educating us on progress on parallel related Russian efforts.

We also want to thank Alan Spero and Greg Simonson for their moral and management support without which the conduct of this work would not have been possible.

Finally, but of great importance, we thank Mary Gualco for the stupendous effort she made in putting this report together. 


\section{References}

Abbas, M., Hydromagnetic wave propagation and excitation of Schumann resonances, Planet. Space Sci., 16, pp. 831-844, 1968.

Aburjania, George D. and George Z. Machabeli, New mechanism for electromagnetic field generation by acoustic waves in partially ionized plasmas, Physics Letters A, 226, pp. 199-204, 1997.

Alfvén, H., On the existence of electromagnetic-hydrodynamic waves, Arkiv. Mat. Astron. Fysik, 29B, No. 2, 1942.

Al'perovich, L. S., B. O. Vugmeister, M. B. Gokhberg, O. A. Pokhotelov, and G. V. Fedorovich, Dokl. AN SSSR, 269, p. 573, 1983.

Al'perovich, L. S., B. O. Vugmeister, M. B. Gokhberg, V. I. Drobzhev et al., Izv. Akad. Nauk SSSR, Fiz. Zemli, 83, No. 11, 1985.

Banister, John R. and William V. Hereford, Observed high-altitude pressure waves from an underground and a surface explosion, J. Geophys. Res., 96, No. D3, pp. 5185-5193, 1991.

Beer, Tom, Atmospheric Waves, John Wiley \& Sons, New York, 1974.

Bernhardt, Paul A., A study of coupling between neutral air motion and the ionosphere, University of California, Los Alamos National Laboratory, LA-9428-MS, June, 1982.

Berthold, W. K., A. K. Harris, and H. J. Hope, World-wide effects of hydromagnetic waves due to Argus, J. Geophys. Res., 65, No. 8, pp. 2233-2239, August 1960.

Blanc, E., Neutral temperature and electron density measurements in the lower E region by vertical HF sounding in the presence of an acoustic wave, Geophys. Res. Lett., 9, 4, pp.450-453, 1982.

Blanc, E., Observations in the upper atmosphere of infrasonic waves from natural or artificial sources: A summary, Annales Geophysicae, 3, 6, pp. 673-688, 1985.

Bretherton, F. P., Lamb waves in a nearly isothermal atmosphere, Quart. J. Met. Soc., 95, pp. 754-757, 1969.

Chetaev, D. N., On the local structure of magnetotelluric field, Izv. AN SSSR, Ser. Fiz. Zemli, 10, pp.105-116, 1978.

Chi, P. J., C. T. Russell, G. Le, W. J. Hughes, and H. J. Singer, A synoptic study of Pc 3, 4 waves using the Air force Geophysical Laboratory magnetometer array, J. Geophys. Res., 101, No. A6, pp. 13,215-13,224, 1996.

Conti, Ugo, Chief Engineer, ElectroMagnetics, Inc., Richmond, California, private communication, 1998.

Cross, Rodney, An Introduction to Alfven Waves, Adam Hilger of IOP Publishing, Philadelphia, p. 21, 1988.

Daniels, Fred B., Siegfried J. Bauer, and Arthur K. Harris, Vertically traveling shock waves in the ionosphere, J. Geophys. Res., 65, No. 6, pp. 1848-1850, June 1960. 
Drobzhev, V. I., V. M. Krasnov, M. Z. Kaliev et al., Vestn. Akad. Nauk Kaz. SSSR, 64, No. 8, 1982.

Evans, L. B., H. E. Bass, and L. C. Sutherland, Atmospheric absorption of sound: theoretical predictions, J. Acous. Soc. Am., 104, pp. 1565-1575, 1971.

Feygin, F. Z., Y. P. Kurchasov, V. A. Troitskaya, D. S. Fligil, and K. Dobes, Method of locating the Pc 1 source and hot plasma parameters in the generation region, Plan. Space Sci., 27, pp. 151-158, 1979.

Fougere, P. F. and C. W. Tsacoyeanes, AFGL magnetometer observations of Mount St. Helens eruption, EOS, 61, N0. 50, pp. 1209-1210, 1980.

Fraser, B. J. and S. S. Wawrzyniak, Source movements associated with IPDP pulsations, $J$. Atmos. Terr. Phys., 40, pp. 1281-1288, 1978.

Fujita, Shigeru, Duct propagation of hydromagnetic waves in the upper ionosphere 2. Dispersion characteristics and loss mechanism, J. Geophys. Res., 93, No. A12, pp. 14,674-14,682, December 1, 1988.

Fujita, Shigeru and Tsutomu Tamao, Duct propagation of hydromagnetic waves in the upper ionosphere 1. Electromagnetic field disturbances in high latitudes associated with localized incidence of a shear Alfvén wave, J. Geophys. Res., 93, No. A12, pp. 14,665-14673, December 1, 1988.

Gal'perin, Y. I., et al., The Alfvén wave excited in the middle latitude magnetosphere by large scale acoustic wave which is propagated in the lower ionosphere, Izv. Earth Phys., 21, p. 877, 1986.

Garrett, C. J. R., Atmospheric edge waves, Quart. J. R. Met. Soc., 95, pp. 731-753, 1969.

Gokhberg, M. B., Strong acoustic wave action. Active experiments in space, ESA-SP-195, pp. 99-110, 1983.

Gokhberg, M. B., V. A. Pilipenko, O. A. Pokhotelov, and S. Parthasarati, Acoustic disturbance from an underground nuclear explosion as a source of electrostatic turbulence in the magnetosphere, Dokl. Acad. Sci. USSR, 313, p. 31, 1992.

Golitsyn, G. S., Damping of small oscillations in the atmosphere due to viscosity and thermal conductivity, Izv., Atmospheric and Oceanic Physics Series, 1, No. 2, pp. 82-89, 1965.

Gossard, Earl E. and William H. Hooke, Waves in the Atmosphere, Elsevier Scientific Publishing Company, New York, 1975.

Greifinger, C. and P. Greifinger, Transmission of micropulsations through the lower ionosphere, J. Geophys. Res., 70, pp. 2217-2231, 1965.

Guglielmi, A., J. Kangas, D. Milling, D. Orr, O. Pokhotelov, Range finding of Alfvén oscillations and direction finding of ion-cyclotron waves by using the ground-based ULF finder, Ann. Geophysicae, 15, pp. 424-429, 1997.

Hayashi, K. S., S. Kokubun, T. Oguti, K. Truruda, S. Mashida, T. Kitamura, O. Saka, and T. Watanabe, The extent of Pc 1 source region in high latitudes, Can. J. Phys., 59, pp. 1097-1105, 1982. 
Hayashi, Kanji, Tatsundo Yamamoto, Susumu Kokubun, Takasi Oguti, Toshihiro Ogawa, Naomoto Iwagami, Tohru Araki, Tai-Ichi Kitamura, Ousuke Saka, Kazuo Makita, Natsuo Sato, Tomiya Watanabe, Robert E. Horita, Donald J. McEwen, Jai S. Kim, and Alv Egeland, Multistation observation of IPDP Micropulsations-Two-dimensional distribution and evolution of the source regions, J. Geomag. Geoelectr., 40, pp. 583-619, 1988.

Jacobs, J. A., Geomagnetic Micropulsations, Springer-Verlag, New York, 1970.

Jacobs, J. A. and T. Watanabe, Propagation of hydromagnetic waves in the lower exosphere and the origin of short period geomagnetic pulsations, J. Atmos. Terr. Phys., 24, pp. 413-434, 1962.

Jacobs, J. A. and T. Watanabe, Trapped charged particles as the origin of short period geomagnetic pulsations, Planet. Space Sci., 11, pp. 869-878, 1963.

Kelly, Michael C., The Earth's Ionosphere, Academic Press, Inc., San Diego, California, 1989.

Knecht, D. J., Daily magnetograms for 1978 from the AFGL network, Publ. AFGL-TR-85-0027, (243), Air Force Geophys. Lab., Hanscom Air Force Base, Mass., 1985.

Krasnov, V. M. and D. L. Shaeffer, Remote monitoring of nuclear explosions during radio sounding of ionosphere over explosion site, talk given at II International Conference on NonProliferation Problems, Kurchatov-City, Republic of Kazakstan, 14-17 September 1998.

Lamb, H., Hydrodynamics, Dover, New York, 6th edition, p. 549, 1945.

Lilly, Jonathan M. and Jeffrey Park, Multiwavlet spectral and polarization analyses of seismic records, Geophys. J. Int., 122, pp. 1001-1021, 1995.

Maeda, K. and S. Kato, Electrodynamics of the ionosphere, Space Sci. Rev., 5, pp. 57-79, 1966.

Main, Ian G., Vibrations and Waves in Physics, Third Edition reprinted, Cambridge University Press, New York, NY, 1994.

Matsushita, S. and Wallace H. Campbell, Physics of Geomagnetic Phenomena, two volumes, Academic Press, New York and London, 1967.

Molchanov, O. A., A possible mechanism for the development of VLH noise radiation in the upper ionosphere of the earth over earthquake foci, Ionosfernye Issledovaniia, 48, pp. 65-99, 1992.

Mushtak, Vadim C., On the suitability of some simplified propagation models for locating transient electromagnetic events within the Schumann frequency range $(6-50 \mathrm{~Hz})$, poster paper, American Geophysical Union Maating, San Francisco, December 1997.

Nickolaenko, A. P. and I. G. Kudintseva, A modified technique to locate the sources of ELF transient events, J. Atmos. And Terr. Phys., 56, No. 11, pp. 1493-1498, 1994.

Ogawa, T., A. C. Fraser-Smith, R. Gendrin, Y. Tanaka, and M. Yasuhara, Worldwide simultaneity of occurrence of a Q-type ELF burst in the Schumann resonance frequency range, $J$. Geomag. Geoelectr., 19, p. 377, 1967.

Ogawa, Tadahiko, Hiroshi Kumagi, and Kenji Sinno, Ionospheric disturbances over Japan due to the 18 May 1980 eruption of Mount St. Helens, J. Atmos. Terr. Phys., 44, No. 10, pp 863-868, 1982. 
Papoulis, Athanasios, The Fourier Integral and Its Applications, McGraw-Hill Book Company, Inc., New York, NY, 1962.

Pierce, E. T., Excitation of Earth-ionosphere cavity resonances by lightning flashes, J. Geophys. Res., 68, No. 13, pp. 4125-4127, July 1, 1963.

Pokhotelov, O. A., V. A. Pilipenko, E. N. Fedorov, L. Stenflo, and P. K. Shukla, Induced electromagnetic turbulence in the ionosphere and the magnetosphere, Physica Scripta, 50, pp. 600-605, 1994.

Pokhotelov, O. A., D. O. Pokhotelov, M. B. Gokhberg, and F. Z. Feygin, Alfvén solitons in the Earth's ionosphere, J. Geophys. Res., 101, No. A4, pp. 7913-7915, April 1996.

Rayleigh, J. W. S., The Theory of sound, Macmillan Company, London, 1984.

Rishbeth, H., The F-layer dynamo, Planet. Space Sci., 19, pp. 263-267, 1971.

Rishbeth, H., The ionospheric E-layer and F-layer dynamos - a tutorial review, J. Atmos. Sol.Terr. Phys., 59, No. 15, pp. 1873-1880, 1997.

Rishbeth, Henry and Owen K. Garriott, Introduction to Ionospheric Physics, Academic Press, Inc., New York, 1969.

Rowland, H. L., M. J. Keskinen, J. S. Villaseñor, and A. Y. Wong, Observations and simulations of VLF harmonic generation with the high-power auroral simulation array, J. Geophys. Res., 101, No. A12, pp. 27,027-27,033, December 1, 1996.

Schumann, W. O., Über die strahlungslosen Eigenschwingungen einer leitenden Kugel, die von einer Luftschicht und einer Ionospherärenhülle umgeben ist, Z. Naturforsch, 7a, p. 149, 1952.

Schumann, W. O. and H. König, Über die Beobachtung von Atmospherics bei geringsten Frequenzen, Naturwissenschaften, 41, p. 183, 1954.

Sentman, D. D., Detection of elliptical polarization and mode splitting in discrete Schumann resonance excitations, J. Atmos. Terr. Phys., 51, No. 6, pp. 507-519, 1989.

Sentman, D. D., Schumann Resonances, Handbook of Atmospheric Electrodynamics, Vol. 1, Hans Volland, Ed., CRC Press, Boca Raton, Florida, 1995.

Shaeffer, D. Lynn, Full wave solution for the transmission of ULF and ELF waves through the ionosphere, Ph.D. thesis, University Microfilms, Ann Arbor, Michigan, 1971.

Smith, L. G., Handbook of Geophysics, Macmillan, New York, 1961.

Stix, Thomas Howard, Waves in Plasmas, American Institute of Physics, New York, 1992.

Stubbe, P., H. Kopka, and M. T. Rietveld, ELF and VLF wave generation by modulated HF heating of the current carrying lower ionosphere, J. Atmos. Terr. Phys., 44, No. 12, pp 1123 $1135,1982$.

Tapley, William C. and Joseph E. Tull, SAC - Seismic Analysis Code Users Manual, University of California, Lawrence Livermore National Laboratory, Revision 4, March 20, 1992. 
Turman, B. N., Detection of lightning superbolts, J. Geophys. Res., 82, p. 2566, 1977.

Warshaw, Stephen I., On a finite amplitude extension of geometric acoustics in a moving, inhomogeneous atmosphere, UCRL-53055, Lawrence Livermore Laboratory, Livermore, California, U.S.A., 94550, September 9, 1980.

Warshaw, Stephen I. and Paul F. Dubois, Preliminary Theoretical Acoustic and RF Sounding Calculations for Mill Race, UCID-19231, Lawrence Livermore Laboratory, Livermore, California, U.S.A., 94550, November 2, 1981.

Warshaw, S. I. and P. F. Dubois, Ionospheric detection of explosions, Energy and Technology Review, University of california, Lawrence Livermore National Laboratory, pp. 38-49, May 1983. 


\section{Appendix A \\ Q-burst Excitation and Energy Flux in the Schumann Frequencies \\ Contained within an Explosion-Induced Hydromagnetic Soliton}

Here we attempt to determine whether an explosion-induced hydromagnetic soliton, such as that reported by Gal'perin et al. (1986), has sufficient energy flux to propagate through the ionosphere and excite a Schumann Q-burst in the neutral atmosphere. The upper threshold of energy flux required for this excitation is $3 \times 10^{-7} \mathrm{~W} \mathrm{~m}^{-2} \mathrm{~Hz}^{-1}$ (Abbas, 1968).

Gal'perin et al. (1986) reported the observation of a hydromagnetic soliton at an altitude of $800 \mathrm{~km}$ about $298 \mathrm{~s}$ after the MASSA experiment. This magnetic perturbation had an amplitude of $117 \mathrm{nT}$, a pulse width of $0.08 \mathrm{~s}$, and a speed of propagation corresponding to the Alfvén speed of $1000 \mathrm{~km} / \mathrm{s}$. The exact waveform of the soliton was not specified. As a reasonable starting point, we fit the classical waveform (See, for example, Main (1994), p. 298) for a soliton to the parameters just mentioned. The result is

$$
\begin{array}{rlrl}
\psi(t, z) & =C \operatorname{sech}^{2} D Z & \\
Z & =V_{A} t-z & \mathrm{~km} \\
C & =1.17 \times 10^{-7} & T \\
D & =4.611 \times 10^{-2} & \mathrm{~km}^{-1} \\
V_{A} & =1000 & \mathrm{~km} / \mathrm{s}
\end{array}
$$

where $\Psi(t, z)$ is the magnetic field perturbation in tesla, $V_{A}$ is the Alfvén speed, and time, $t$, is specified in seconds. We take the origin $(\mathrm{z}=0)$ of the spatial coordinate to be the point of observation, viz., $800 \mathrm{~km}$ altitude. We also take the origin of time $(\mathrm{t}=0)$ as the time of observation. A plot of this magnetic perturbation as a function of time at the spatial origin is shown in Fig. A-1. Note that there is some ambiguity in the definition of pulse width. The Russians do not specify how the pulse width was determined. Here we consider it to be the full width of the pulse at the time at which the amplitude has decreased to 0.1 of the value of the peak amplitude. Another definition of pulse width, such as the full width of the pulse at one-half maximum, for example, does not lead to significantly different results, which we address below.

The Poynting flux, $\mathrm{S}$, in $\mathrm{W} / \mathrm{m}^{2}$ is given by

$$
S=\frac{\psi^{2} V_{A}}{\mu_{0}}
$$

where $\mu_{0}$ is the magnetic permeability of free space, $4 \pi \times 10^{-7} \mathrm{H} / \mathrm{m}$. We calculate the energy flux, $I_{F}$, with the use of Parseval's Theorem (Papoulis, 1962, p. 27): 


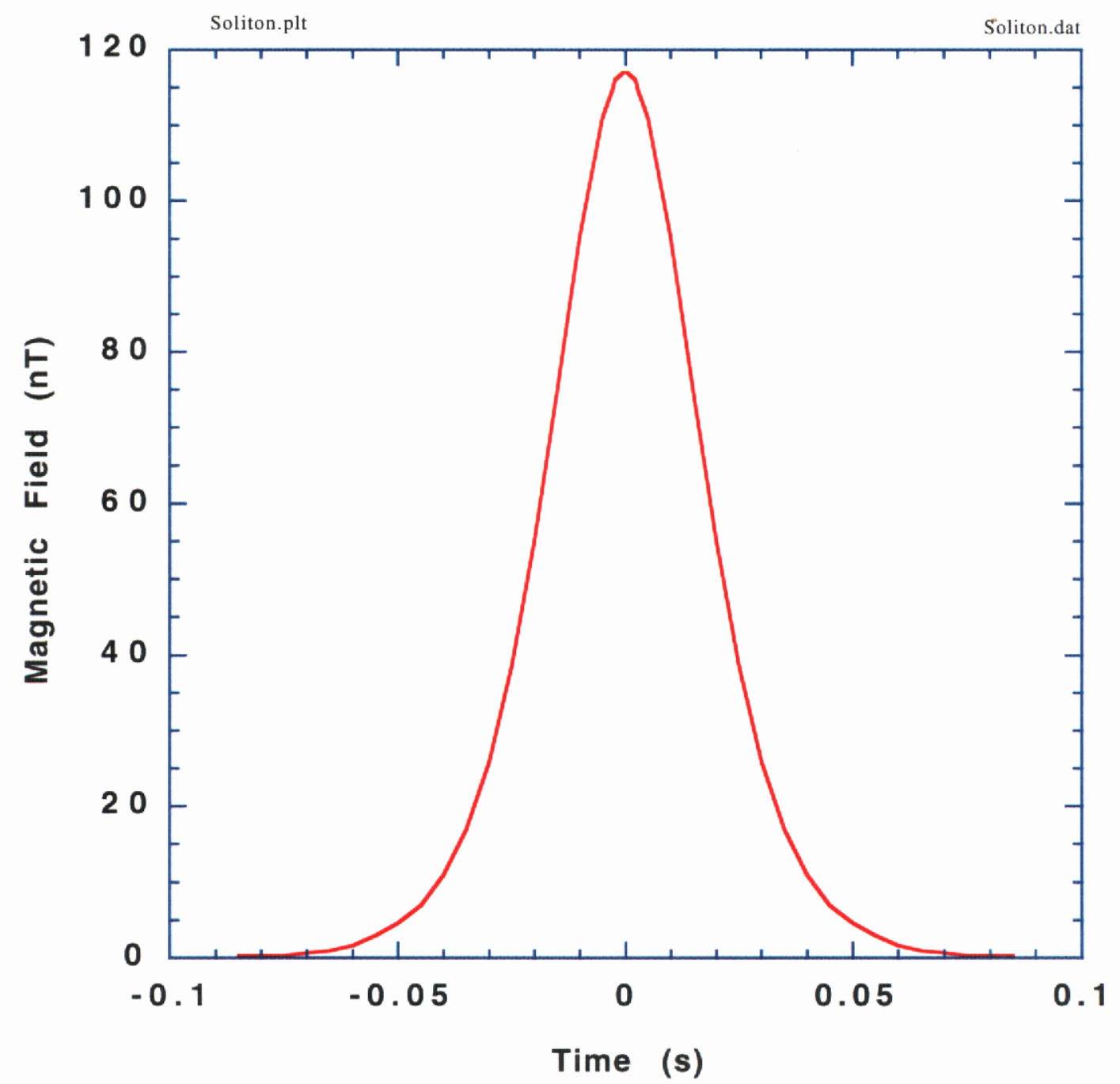

Figure A-1. Soliton waveform as a function of time. The fit was made to a classical soliton wave shape (Main, 1994) with parameter values reported by Gal'perin et al. (1986). The pulse width was taken to be the width at which the amplitude was 0.1 times the value of the peak amplitude. 


$$
I_{E}=\frac{V_{A}}{\mu_{0}} \int_{-\infty}^{+\infty}|\psi(t)|^{2} d t=\frac{V_{A}}{\mu_{0}} \frac{1}{2 \pi} \int_{-\infty}^{+\infty} A^{2}(\omega) d \omega,
$$

where $A(\omega)$ is the magnitude of the Fourier transform of $\Psi(t)$, and $A^{2}(\omega)$ is the energy spectrum of $\psi(t)$. (The quantity $A(\omega)$ is derived in Appendix B.) We calculate the left hand integral of Eq. (A-3) with the use of Eq. (A-1) to obtain

$$
\begin{aligned}
& \mathrm{I}_{E}=\frac{\mathrm{C}^{2} \mathrm{~V}_{\mathrm{A}}}{\mu_{0} \mathrm{DV} \mathrm{V}_{\mathrm{A}} \int_{-\infty}^{+\infty} \operatorname{sech}^{4} \mathrm{x} d \mathrm{x},} \\
& \mathrm{I}_{\mathrm{E}}=\frac{\mathrm{C}^{2}}{\mu_{0} \mathrm{D}}\left\{\left.\tanh x\right|_{-\infty} ^{+\infty}-\left.\frac{\tanh ^{3} x}{3}\right|_{-\infty} ^{+\infty}\right\}, \text { and } \\
& \mathrm{I}_{E}=\frac{4}{3} \frac{\mathrm{C}^{2} \mathrm{~V}_{\mathrm{A}}}{\mu_{0}} \frac{1}{\mathrm{DV} V_{A}} .
\end{aligned}
$$

Substituting values for the various constants, we obtain

$$
\mathrm{I}_{\mathrm{E}}=3.15 \times 10^{-4} \mathrm{~W} \mathrm{~m}^{-2} \mathrm{~Hz}^{-1} .
$$

Not all of this energy is available, however, for exciting the Q-burst. Only that amount, $\mathbf{I}_{S}$, which resides in the Schumann resonance is effective.

The quantity $I_{S}$ is obtained from

$$
\mathrm{I}_{\mathrm{S}}=\frac{\mathrm{V}_{\mathrm{A}}}{\mu_{0} \pi} \int_{\omega_{\mid}}^{\omega_{\mathrm{u}}} \mathrm{A}^{2}(\omega) \mathrm{d} \omega \mathrm{W} \mathrm{m}^{-2} \mathrm{~Hz}^{-1},
$$

where the integral has been multiplied by 2 to include negative frequencies; $\omega_{1}$ and $\omega_{u}$ are the lower and upper angular frequencies, respectively, which define the width of the fundamental Schumann resonance. These quantities are obtained from the definition of the $\mathrm{Q}$ of the earthionosphere waveguide, giving,

$$
\mathrm{Q}=\frac{\omega_{0}}{2 \Delta \omega}=\frac{2 \pi f_{0}}{2\left(\omega_{u}-\omega_{1}\right)}
$$

where $f_{0}$ is the fundamental Schumann resonance $(7.8 \mathrm{~Hz})$. We take the resonance peak to be symmetric about $\mathrm{f}_{0}$ so that

$$
\omega_{u, 1}=\omega_{0} \pm \frac{\Delta \omega}{2}
$$

In general, $Q$ lies between 3 and 6. Here we choose $Q=5$. From Eqs. (A-9) and (A-10), we calculate 


$$
\omega_{u}=(1.05) \omega_{0}
$$

and

$$
\omega_{1}=(0.95) \omega_{0} .
$$

We introduce a dimensionless frequency, $\mathrm{p}$, defined by

$$
p=\frac{\omega}{D V_{A}},
$$

which we use to transform Eq. (A-8) to

$$
I_{S}=\frac{V_{\Lambda}}{\pi \mu_{0}} D V_{A} \int_{\rho_{1}}^{p_{u}} A^{2}(p) d p,
$$

where $\mathrm{p}_{1}=1.0097, \mathrm{p}_{\mathrm{u}}=1.1160$, and

$$
A^{2}(p)=\left(\frac{2 \pi C}{V_{A} D}\right)^{2} A_{N}^{2}(p)
$$

with

$$
A_{N}^{2}(p)=\frac{p^{2} e^{-\pi p}}{\left(1-e^{-\pi p}\right)^{2}}
$$

where $A_{N}^{2}(p)$ is the normalized spectrum expressed in terms of dimensionless frequency, $p$. The spectrum $A^{2}(p)$ is derived in Appendix $B$ and $A_{N}^{2}(p)$ is shown here in Fig. A-2. The frequency interval corresponding to the Schumann resonance is also identified in Fig. A-2. For the fundamental Schumann frequency, $\mathrm{p}_{1}$ and $\mathrm{p}_{\mathrm{u}}$ are sufficiently large that the denominator of $\mathrm{Eq}$. (A-16) can be approximated by unity, and Eq. (A-14) then yields

$$
I_{S} \approx\left[-\frac{K}{\pi} e^{-\pi p}\left\{p^{2}+\frac{2}{\pi^{2}}(\pi p+1)\right\}\right]_{p_{1}}^{p_{u}},
$$

where

$$
K=\frac{1}{\pi} \frac{V_{A}}{\mu_{0}} D V_{A}\left(\frac{2 \pi C}{D V_{A}}\right)^{2}=2.97 \times 10^{-3}
$$

Evaluation of Eq. (A-17) for the fundamental Schumann resonance yields

$$
\mathrm{I}_{\mathrm{S}}=1.26 \times 10^{-5} \mathrm{Wm}^{-2} \mathrm{~Hz}^{-1}
$$




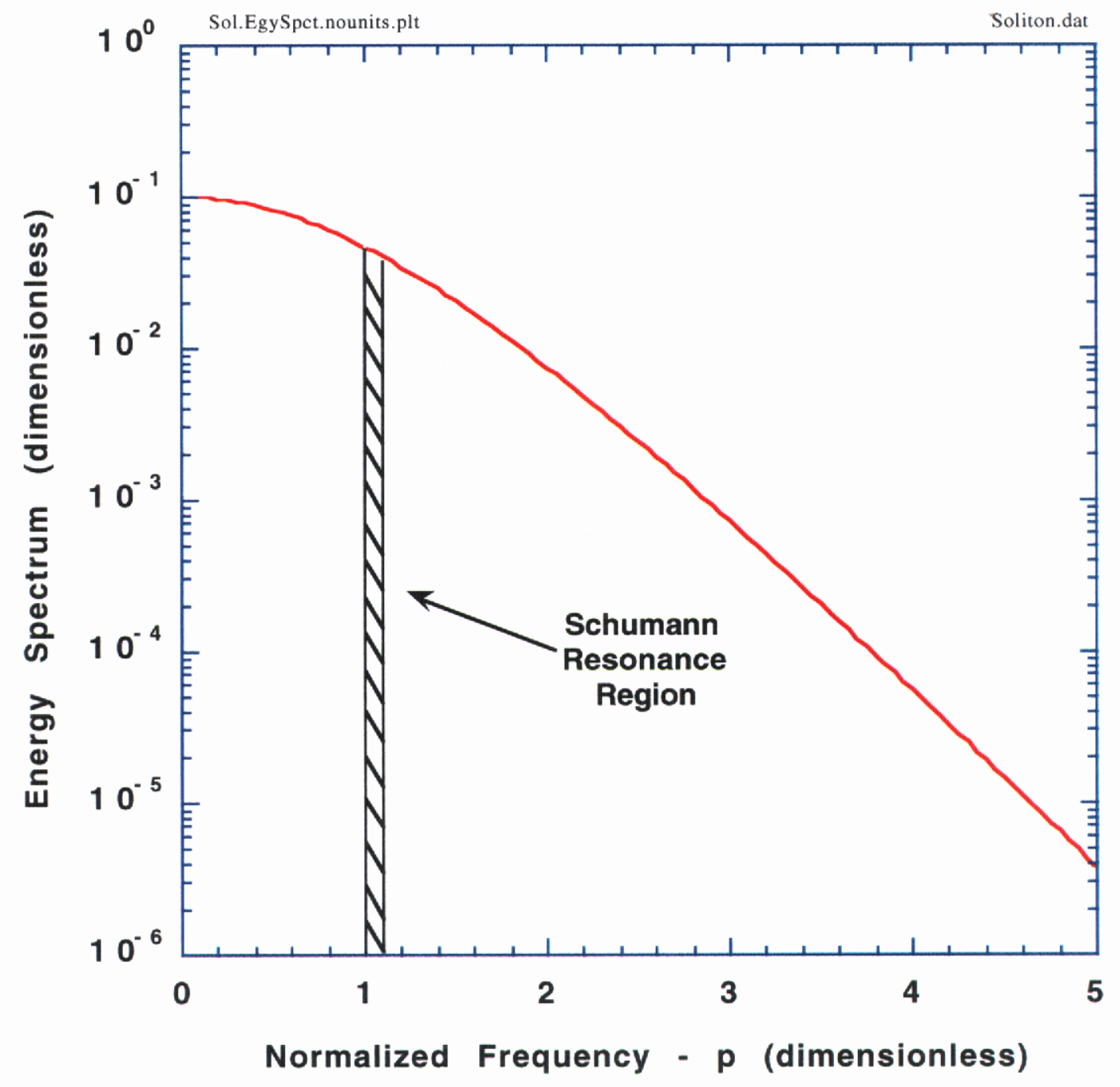

Figure A-2. Normalized energy spectrum of the soliton versus dimensionless frequency, $p$. 
We also have

$$
\frac{I_{S}}{I_{E}}=4.01 \times 10^{-2}
$$

In other words, 4 percent of the total soliton energy flux resides in the fundamental Schumann resonance. We see that the energy flux associated with the Schumann fundamental resonance contained within the explosion-induced soliton is 42 time larger than the threshold value quoted above that was determined by Abbas (1968). Consequently, there is more than sufficient energy flux for the soliton to excite a Q-burst.

If we had defined the pulse width of the soliton to be the width of the pulse at one-half the maximum value of the pulse, we would have obtained

$$
\mathrm{I}_{\mathrm{S}}=9.50 \times 10^{-6} \mathrm{~W} \mathrm{~m}^{-2} \mathrm{~Hz}^{-1}
$$

and

$$
\mathrm{I}_{\mathrm{E}}=5.59 \times 10^{-4} \mathrm{~W} \mathrm{~m}^{-2} \mathrm{~Hz}^{-1}
$$

In this case, the energy flux in the fundamental Schumann resonance is 1.7 percent of the total in the soliton, and is 32 times larger than Abbas's threshold. Once again, there is more than sufficient energy flux to excite a Q-burst. 


\section{Appendix B}

\section{Derivation of Fourier Transform and Energy Spectrum of a Soliton}

We desire to obtain the Fourier transform of

$$
\begin{aligned}
& \psi(t)=C \operatorname{sech}^{2} D Z(t) \\
& Z(t)=V_{A} t-z
\end{aligned}
$$

The Fourier transform, $\tilde{\psi}(\omega)$, of $\psi(t)$ is given by

$$
\begin{aligned}
& \tilde{\psi}(\omega)=\int_{-\infty}^{+\infty} d t e^{-j \omega t} \psi(t) \\
& \tilde{\psi}(\omega)=C \int_{-\infty}^{+\infty} d t e^{-j \omega t} \operatorname{sech}^{2} D Z(t)
\end{aligned}
$$

We shift the frequency by substituting $s=D Z(t)$, so that

$$
t=\left(\frac{s}{D}+z\right) \frac{1}{V_{A}}, \quad V_{A}>0
$$

Then

$$
\begin{aligned}
& \tilde{\psi}(\omega)=\frac{C}{V_{A} D} \int_{-\infty}^{+\infty} d s \exp \left[-j \omega\left(\frac{s}{D V_{A}}+\frac{z}{V_{A}}\right)\right] \frac{1}{\cosh ^{2} s} \\
& \tilde{\psi}(\omega)=\frac{C}{V_{A} D} e^{-j \frac{\omega z}{V_{A}}} \int_{-\infty}^{+\infty} d s e^{-j p s} \frac{1}{\cosh ^{2} s},
\end{aligned}
$$

where

$$
p=\frac{\omega}{D V_{A}}
$$

which may be considered a dimensionless frequency. Now we have

$$
\tilde{\psi}(p)=\frac{C}{V_{A} D} e^{-j p z D} \int_{-\infty}^{+\infty} d s e^{-j p s} \frac{1}{\cosh ^{2} s} .
$$

This integral has poles at

$$
s_{n}=j \frac{\pi}{2}(1+2 n), \quad n=0, \pm 1, \pm 2, \ldots
$$


We can complete the contour for $\operatorname{Im} s<0, p>0$, and for $\operatorname{Im} s>0, p<0$. Make the substitution

$$
s^{\prime}=-j \frac{\pi}{2}+s
$$

so that $\cosh s=\sinh s^{\prime}$. Now consider

Case I, $p>0$

$$
\tilde{\psi}(p)=\frac{C}{V_{A} D} e^{-j p z D} \sum_{n=1}^{\infty} \oint d s^{\prime} \frac{e^{-j p s^{\prime}}}{\sin ^{2}\left(j s^{\prime}\right)} e^{\frac{\pi}{2} p}
$$

which becomes

$$
\tilde{\psi}(p)=\frac{C}{V_{A} D} e^{-j p z D+\frac{\pi}{2} p} \sum_{n=1}^{\infty} \frac{2 \pi j\left[-j p e^{-j p(j \pi n)}\right]}{+1}
$$

On further inspection we obtain

$$
\tilde{\psi}(p)=\frac{C}{V_{A} D} e^{-j p z D+\frac{\pi}{2} p}(2 \pi j)(-j p) \sum_{n=1}^{\infty} e^{-p n \pi}
$$

or

$$
\tilde{\psi}(p)=\frac{2 \pi C}{V_{A} D} e^{-\left(j z D+\frac{\pi}{2}\right) p} \frac{p}{1-e^{-\pi p}} .
$$

Case II, $\mathrm{p}<0$

$$
\tilde{\psi}(p)=\frac{C}{V_{A} D} e^{-j p z D+\frac{\pi}{2} p} \sum_{n=0}^{\infty} \frac{2 \pi j\left[-j p e^{-j p(j \pi n)}\right]}{-1}
$$

or

$$
\tilde{\psi}(p)=\frac{2 \pi C}{V_{A} D} e^{-\left(j z D-\frac{\pi}{2}\right) p} \frac{-p}{1-e^{\pi p}} .
$$

For positive and negative $\mathrm{p}$ together, we have

$$
\tilde{\psi}(p)=\frac{2 \pi C}{V_{A} D} \frac{|p| e^{-\frac{\pi}{2}|p|}}{1-e^{-\frac{\pi|p|}{2}}} e^{-j z D p},
$$

where $p$ is defined by Eq. (B-7). 
The energy spectrum, $A^{2}(p)$, is given by the square of the magnitude of Eq. (B-17), viz.,

$$
A^{2}=\left(\frac{2 \pi C}{V_{A} D}\right)^{2} A_{N}^{2}(p)
$$

where

$$
A_{N}^{2}(p)=\frac{p^{2} e^{-\pi|p|}}{\left(1-e^{-\pi|p|}\right)^{2}}
$$

The magnitude, $A_{N}(p)$, of the Fourier transform of $\psi(t)$ is plotled in Fig. B-1 as a function of dimensionless frequency, $\mathrm{p}$. 


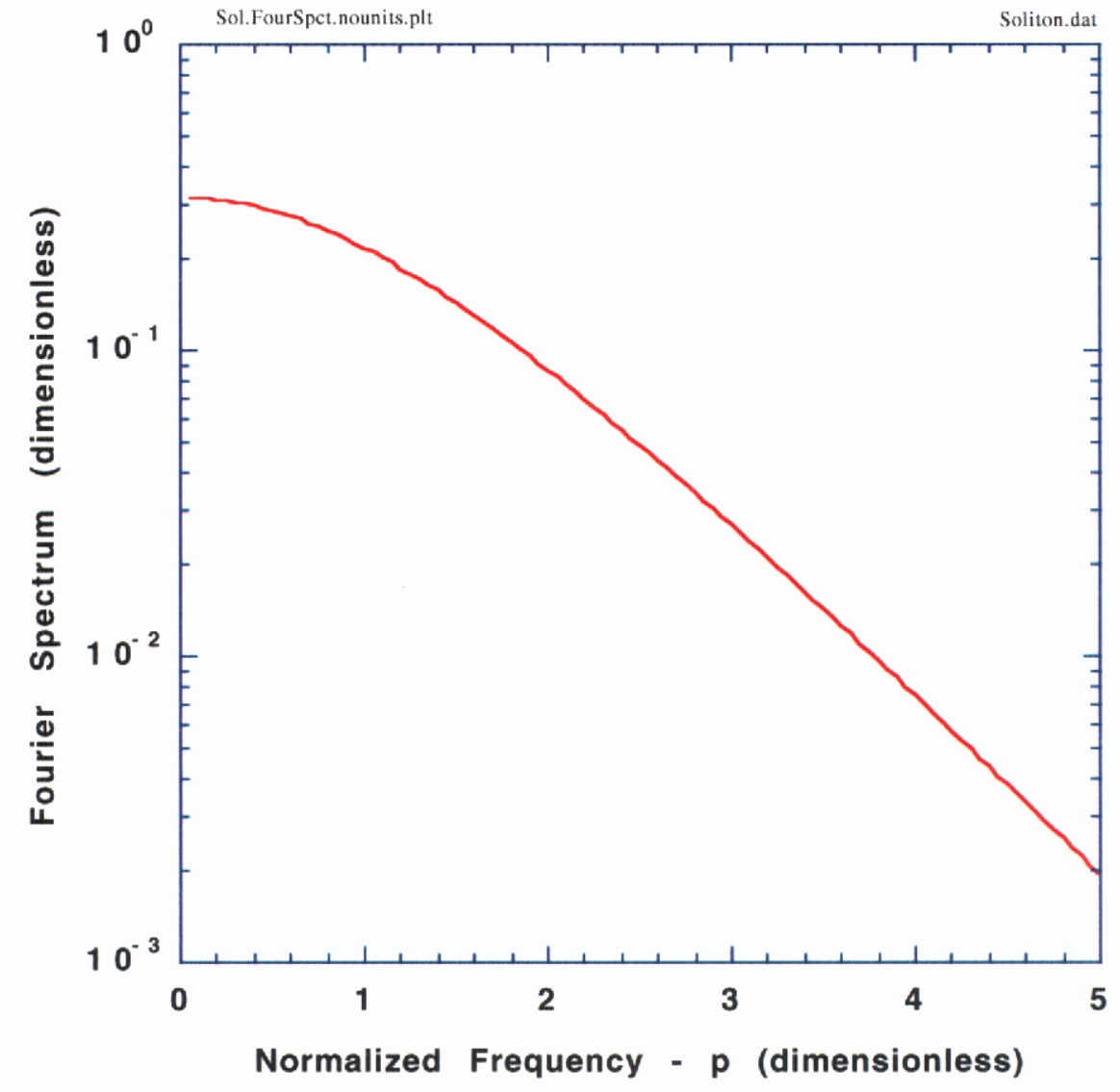

Figure B-1. Normalized magnitude of the Fourier transform of the soliton as a function of dimensionless frequency, $p$. 